\title{
Contents
}

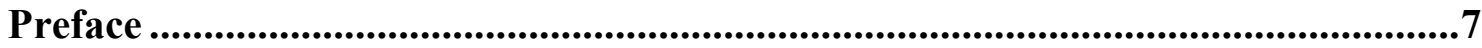

I. Process and Universals

Process Philosophy and the Problem of Universals

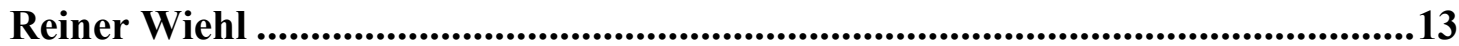

Abstraction and Individuation in Whitehead and Wiehl

Anderson Weekes.......................................................................................................39

II. Nature and Subjectivity

Prehension

John B. Cobb, Jr. ..................................................................................................123

Whitehead, Hume and the Phenomenology of Causation

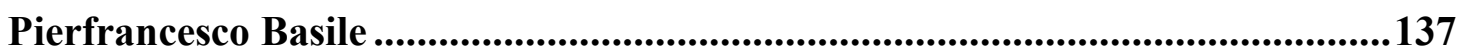

Subjectivity, System and Intersubjectivity

Joseph A. Bracken

Maxwell's Field and Whitehead's Events

Leemon B. McHenry.......................................................................................177

III. Ethics and Civilization

Morality and Scientific Naturalism

David Ray Griffin ..........................................................................................193

Can Specific Rules be Deduced from Moral Principles?

John W. Lango

Ethical Quantities

Nicholas Rescher

The Wand of the Enchanter

George Allan

Creativity, Efficacy and Vision

Michel Weber. 
IV. Psychology and Phenomenology

Truthfulness and Memory

Michael Hampe

Empathy and Reliability

Bernd Weidmann

On Gadamer, Phenomenology and Historical Relativism

Alon Segev....

Max Scheler on Love and Hate

Helmut Maaßen. .335

About the Authors. .345

Analytical Table of Contents

349

Process Thought Series. 


\section{Abstraction and Individuation in Whitehead and Wiehl: A Comparative Historical Approach Anderson Weekes}

In the early twentieth century, Alfred North Whitehead (to the chagrin of many) conceived a philosophical cosmology in the grand tradition of western metaphysics. * He believed there was a need for such a cosmology, properly updated to incorporate important scientific developments such as quantum theory and relativity theory. He was unembarrassed to take as models for this project the likes of Plato, Aristotle, Spinoza, and Bergson. The topics were traditional; the theorems were not. Actuality and potentiality, being and becoming, subjects and objects, universals and particulars, internal and external relations-these familiar tropes of classical philosophy found expression in a natural philosophy clearly indebted to projective geometry, special relativity, universal algebra and mathematical logic. This paper looks at one of the most ancient and abstruse of perennial philosophical topics, the career of which intersects with every great metaphysical system: the principle of individuation. Whitehead's contribution to this subject is examined in light of the tradition he emulates. We want to know what Whitehead's theory of individuation is, but this will be unilluminating if we don't know what issues motivate philosophers to take one position or another on a question so abstract. What are the basic positions that have been taken in the traditional debate? Why were they taken? What should be the parameters of an inclusive taxonomy

* In this paper, reference is made to the following editions of Whitehead's works by means of the following standard abbreviations: AI: Adventures of Ideas (New York 1967); CN: Concept of Nature (Cambridge 1978); PNK: An Enquiry Concerning the Principles of Natural Knowledge (New York 1982); PR: Process and Reality. An Essay in Cosmology, corrected edition, edited by D. R. Griffin and D. Sherburne (New York 1978); S: Symbolism. Its Meaning and Effect (New York 1985); SMW: Science and the Modern World (New York 1967). 
of theories of individuation? Where would Whitehead fit in such a scheme? These are the guiding questions that receive at least partial answers here.

The first part sets the stage by laying out the necessary analytic vocabulary. I do this by tracking the many different meanings of abstractness (or universality) that Whitehead distinguishes. Since abstractness and individuality are correlative counter-notions, each kind of abstractness delineates individuality somewhat differently. These fine delineations will prove very useful in keeping track of the traditionally debated theoretical alternatives. Since these distinctions have been a focus of Reiner Wiehl's interpretations of Whitehead, I take as my point of departure his paper "Process Philosophy and the Problem of Universals" (PU). I begin with a central, but difficult passage in Professor Wiehl's essay concerning the different senses in which universals can be said to "transcend" particulars, relying for guidance on an earlier essay of his, "Prozesse und Kontraste" (PK), and on the chapter on abstraction in SMW. While my interpretation of Professor Wiehl's difficult paper must remain tentative, the clarification he facilitates of Whitehead's analytic apparatus in SMW is more secure. In part two I examine the contrasting theories that have dominated the philosophical tradition regarding the relationship of intuition and thought, which sheds light on the question of individuation. Part three turns to individuation proper, offering a taxonomy of traditional positions. Finally, in part four, I examine Whitehead's own treatment of individuation in CN, SMW and PR in order to establish the precise points of agreement and disagreement with the traditional positions delineated in parts two and three.

A brief word need to be said about my method of presentation, which follows the order of discovery, dwelling on the structure of the problems in order then to explore alternative solutions (mainly by retracing the dialectic of evolving arguments and counter-arguments in the history of philosophy). This method finds its justification in the nature of the problems considered. Abstract philosophical problems are entirely discursive phenomena and their existence depends on an argument or set of arguments for their existence, giving their specific discursive genesis a primacy that no solution, however satisfying it may seem, can ever annul.

I note in advance that the argument in each part of this paper reveals the same two positions as fundamental alternatives. Since the language required for explicitness and clarity about such an abstract problem is of necessity somewhat cumbersome, it will be helpful to fix the relevant terminology at the outset. The basic question is whether individuality is to be understood as a unique extreme of specificity or as a singularity somehow beyond or more than specificity. By specificity is meant the kind 
of identity that can be specified without recourse to any indexical (tokenreflexive) acts of reference, that is, by a description that presupposes acquaintance with universals alone. (Whether we can be acquainted with universals without having been previously acquainted with particulars is immaterial. The question is whether, once we are acquainted with universals, we can successfully pick out an individual using universals alone. If so, then in such a case individuality coincides with unique specificity.)

The identification of individuality with unique specificity is sometimes called "essentialism" because it envisions the individual as being nothing more than a unique complex or intersection of universals ("essences"). ${ }^{1}$ Each individual will therefore differ in some perfectly definable way from every other individual. All individuals, in other words, will differ in specie (in type) from one another. In this case, to be individual rather than universal (or concrete rather than abstract) means being the last or most specific species (one of the infimae species) of a given genus, which would be comparable to being the last and most complex member (the vertex) of what Whitehead calls an abstractive hierarchy. Contrariwise, if a description employing universals alone fails to pick out an individual, then by implication individuality is something more than extreme specificity. The question naturally arises what this something more is. How can what is already typologically unique be further individuated into numerically distinct instances? Since the answer to this question obviously cannot consist in specifying what transcends specificity, we should not be surprised that the question elicits abstruse and exceedingly subtle responses. The difference between the two positions becomes especially complicated when essentialism abandons the traditional Aristotelian idea that the complexity of a thing's essence is necessarily finite. In that case there is no "last" term in the specification of the essence. The distinction between singularity and infinite specificity is more elusive than the distinction between singularity and unique finite specificity, as the discussion of Whitehead's theory of individuation in part four will show. ${ }^{2}$ 


\section{The Abstractness and Transcendence of Universals}

The core insight of Professor Wiehl's paper has to do with the meaning of the traditional concept of universals. This concept suffers from a fundamental ambiguity. Even process philosophy, he believes, is not immune to this failing. It inherits the failure of the philosophical tradition to distinguish unequivocally between two very different ways that something can be said to transcend particulars and hence to be abstract or universal. This is stated, but not altogether explained, in his paper when he refers at the close of part one to the "ambiguity of traditional process philosophy," which, he says, "has to do with the meaning of transcendence." Since "universals," "abstractions," and "eternal objects" are roughly co-extensive notions (in Whitehead and Wiehl), all defined by the same relation of "transcendence," suffer from the same ambiguity. Bearing this in mind, we can begin to unpack Professor Wiehl's meaning simply by collating texts in Whitehead and in Professor Wiehl's earlier writings bearing on the ambiguity of any of these rubrics.

In PU Professor Wiehl states, somewhat enigmatically:

One of the two meanings of transcendence construes it in reference to the totality of a given hierarchy of concepts and value-determinations. The other meaning arises from the primal relationship [...] that the hierarchy of concepts and values enters into with things or events. It involves the transcendence of a part of the hierarchy-in the extreme case, the transcendence of the highest or of the lowest in the hierarchy-vis-à-vis the being for which the hierarchy functions as a predicative order.

Happily, we can turn to an earlier essay for some elucidation here. In PK Professor Wiehl distinguished three ways that Whitehead's eternal objects can be said to be abstract. ${ }^{4}$ First, eternal objects are abstract insofar as each one can be considered apart from its relationships with all other eternal objects. Secondly, they are abstract insofar as they are possibilities for realization considered apart from the actual givenness of a real thing. Thirdly, they are abstract insofar as they are unspecific determinations considered apart from individuating factors (such as, for example, generic predicates). I suggest that the two meanings of transcendence distinguished in the quotation above correspond to the second and third meanings of abstractness noted in PK: 
Table I

\begin{tabular}{|c|c|}
\hline "Process and Universals" (PU) & "Prozesse und Kontraste" (PK) \\
\hline Transcendence of Universals Type 1 & $\begin{array}{c}\text { Abstraction Type 1 } \\
\text { EO apart from Its Relationships to All } \\
\text { Other Eos }\end{array}$ \\
\hline Transcendence of Universals Type 2 & $\begin{array}{c}\text { Abstraction Type 2 } \\
\text { Realizations in Actual Instances }\end{array}$ \\
\hline EO as Unspecific Determination apart \\
from Individuating Factors
\end{tabular}

$(E O=$ Eternal Object $)$

Let's pursue the triad from PK for the moment. Since these distinctions are meant to gloss Whitehead's discussion of abstraction in chapter ten of SMW, it makes sense for us to seek their basis in this critical text. Professor Wiehl's first kind of abstraction, I suggest, corresponds to what Whitehead calls the "individual essence" of the eternal object, which Whitehead contrasts with its "relational essence." According to its individual essence, the eternal object "is what it is [...] considered in respect to its uniqueness," while the relational essence involves "its reference to other eternal objects." 7 The individual essence abstracts from the eternal object's relations to other eternal objects, and this abstraction is justified because "eternal objects are devoid of real togetherness: they remain within their 'isolation'."

The second type of abstractness seems to correspond to what Whitehead has to say about eternal objects as "entities which transcend [the] immediate occasion [of cognition] in that they have analogous or different connections with other occasions of experience." 9 As possibilities for realization, eternal objects are capable of multiple instantiation. Any instance of an eternal object thus transcends its particular instance as something identically instantiated elsewhere or inherently capable of such multiple instantiation. It is by way of this inherent possibility for instantiation that unrealized eternal objects (whether completely unrealized or just unrealized in a given case) are, according to Whitehead, able to become relevant to occasions that do actually exist. ${ }^{10}$

These first two types of abstractness form a necessary couplet defined by contrast. Whitehead proposes a relational ontology according to which 
relations are constitutive of what things are. Therefore, nothing can be concrete apart from its relations. Since there are two kinds of relations, external and internal, and eternal objects possess both of them, there will evidently be at least two ways for an eternal object to be abstract, depending on which type of relation is abstracted from. Eternal objects have internal relation with other eternal objects (e.g., red is not blue and wouldn't be red any more if it were, so its difference from anything not-red is an internal relation; red and blue are both colors and couldn't be red and blue without having this much in common with one another, so their generic similarity is an internal relation). And, eternal objects have external relations with the actual entities that instantiate them (it makes no difference to red whether anything is red right now, so its being instantiated is an external relation as far as red is concerned). The eternal object apart from its internal relations yields abstraction in sense one; the eternal object apart from its external relations is abstraction in sense two. The possibility of these two kinds of abstraction guarantee that eternal objects have a definite identity that is not context dependent (does not vary in relation to other eternal objects or depend on their concrete realization).

The third type of abstractness seems to correspond to what Whitehead means when he says that the distinguishing characteristic of the mental is the "abruptness" of "a finite complex concept."11 This is one of Whitehead's most original contributions to philosophy and requires some careful elucidation. Along the way we will distinguish yet two more senses of "abstract," giving us a total of no less than five.

First of all, to understand what Whitehead has in mind when he describes "abruptness" as a kind of abstraction, we must examine an important distinction he makes between two diametrically opposed measures of abstraction. He employs this distinction to construct a new oppositional couplet, in which abstraction as abruptness is one of the contrasted terms. Just as senses one and two are terms of a necessary couplet whose respective meanings are illuminated by their contrast, so too with abruptness and its opposite. In order to understand abruptness, then, we will have to look at the kind of abstraction with which it is paired by contrast. These latter two meanings of abstraction will become senses three and four in our tally.

The diametrically opposed measures of abstraction Whitehead distinguishes are "abstraction from actuality" and "abstraction from possibility." 12 Whitehead stresses that "some confusion of thought has been caused" because they run in "opposite direction[s]."13 Let's take as an example the description "a round red rubber ball." This description is more concrete than "a round rubber ball," which again is more concrete than "a 
round ball." The more complex description is less abstract because it more closely approximates the plenary detail of the actual concrete individual. But by the same token it is able to apply to fewer things. It does not just apply to fewer things in fact. Rather, it is capable of applying to fewer things. In this latter respect, therefore, it can also be said to be more abstract in a well defined sense: through greater specificity it abstracts more from the scope of possibility and concentrates on a narrower scope of potential realization. Since a description achieves greater specificity through greater complexity, complexity is a measure of abstraction from possibility, while simplicity is a measure of abstraction from actuality. This same insight is expressed in ordinary logic books by saying that the extension and intension (or "content") of a class-concept bear an inverse relation to one another. Whitehead puts it this way:

[W]ith a high grade of complexity we gain in approach to the full concreteness of [an actual occasion], and with a low grade we lose in this approach. Accordingly the simple eternal objects represent the extreme of abstraction from an actual occasion; whereas simple eternal objects represent the minimum of abstraction from the realm of possibility. It will, I think, be found that, when a high degree of abstraction is spoken of, abstraction from the realm of possibility is what is usually meant-in other words, an elaborate logical construction. ${ }^{14}$

Returning to Wiehl's definitions, it should be obvious that abstractness in his senses (1) and (3) are both kinds of abstraction from actuality. It should also be obvious that abstractness in Wiehl's sense (1), that is, the simple eternal objects in their isolation, will coincide with the greatest abstraction from actuality, even if this is not the hallmark by which sense one is defined. (It is defined by the isolation of eternal objects from one another.) It is abstraction in sense three that is defined by the hallmark of abstraction from actuality. But note that it is defined by abstraction from actuality as such, which means any degree of abstraction from actuality. This establishes a clear conceptual distinction between senses one and three, even if the extension of $A_{1}$ is wholly included in that of $A_{3}$ :

$\mathrm{A}_{1}=$ Abstraction of Eternal Object from Its Relations to All Other Eternal Objects (implying greatest abstraction from actuality);

$\mathrm{A}_{3}=$ Any Degree of Abstraction from Actuality (implying abstraction of eternal object from its relations to at least some of the other eternal objects). ${ }^{15}$

We have also established a clear distinction between senses one and two (abstraction from internal versus abstraction from external relations). But we wanted most to understand the difference between senses two and three. Remember that our goal is to understand the difference between the two kinds of transcendence broached in PU and that my hypothesis is they 
correspond to abstraction in senses two and three in PK, which is a more manageable text because its bearing on Whitehead's own distinctions is more transparent. However, establishing the conceptual distinction between senses two and three is not as straightforward as the other distinctions. Isn't abstraction in sense two defined as abstraction from actuality just as much as sense three?

In order to understand the difference between senses two and three we must understand what it means for sense three to be defined by the concept of abruptness, and this, as noted, requires us to examine the concept Whitehead contrasts with abruptness, which is the concept of the extremity of abstraction from possibility. Abruptness is abstraction in sense three, and the extreme of abstraction from possibility is the fourth sense of abstractness that we must consider. Once we understand how senses three and four form an oppositional couplet, we will be positioned to come back to sense two (the abstraction of eternal objects from their external relations) and see how it differs from abruptness. As an oppositional couplet, sense three versus sense four may seem lopsided since the one term is abstraction from actuality (of any degree), while the other is specifically the extreme of complete abstraction from possibility. Sense one versus sense four might seem to be a more balanced couplet (because they are contraries: extreme abstraction from actuality versus extreme abstraction from possibility), but we will see that it is three and four that form the appropriate contrast. This begins to make sense as soon as we realize that they are in fact contradictories. For extremity of abstraction from possibility means no abstraction from actuality and thus turns out to be another name for concreteness, so the contrast in question is some (any) abstraction from actuality versus no abstraction from actuality, which simply means nonconcrete versus concrete (or, as we shall shortly see, finite versus infinite abstractive hierarchy of eternal objects).

Whitehead's description of what I am subjoining to Wiehl's list as sense (4) is logically precise. First Whitehead defines the notion of an "abstractive hierarchy of concepts (or eternal objects) based upon a set $g$ of simple eternal objects." $G$ can be a finite or an infinite set of simple eternal objects. The abstractive hierarchy is a set of combinations of those simple eternal objects, and these combinations can be finite or infinite. Where, for example, the combinations are an open set defined by recursive operations, the abstractive hierarchy will be infinite, regardless of whether the base is finite or infinite, and where the combinations are finite, Whitehead defines the hierarchy as finite, again regardless of whether the base is finite or infinite. He then tells us what the extremity of abstraction 
from possibility is; that is, he tells us what individuality means for the philosophy of organism:

In any actual occasion $a$, there will be a group $g$ of simple eternal objects which are ingredient in that group in the most concrete mode. This complete ingredience in an occasion, so as to yield the most complete fusion of individual essence with other eternal objects in the formation of the individual emergent occasion, is evidently of its own kind and cannot be defined in terms of anything else. But it has a peculiar characteristic which necessarily attaches to it. This characteristic is that there is an infinite abstractive hierarchy based upon $g$ which is such that all its members are equally involved in this complete inclusion of $a$ [understand a subjective genitive: "involved in this complete inclusion of (them by) $a] .{ }^{17}$

The significance of this does not become clear until Whitehead adds: "The existence of such an infinite abstractive hierarchy is what is meant by the statement that it is impossible to complete the description of an actual occasion by means of concepts."18 An actual individual is something no finite description can capture: no finitely employed inventory of concepts, no finite set of combinations, no finite iteration of their combinations. It is infinitely complex or infinitely nuanced (depending on how you look at it). This is abstraction in sense four: extreme of abstraction from possibility, i.e., actual concrete individuality. ${ }^{19}$ Simply by negating this concept of extremity of abstraction from possibility we arrive at a perfectly welldefined sense of abstractness from actuality: any finite description, no matter how complex, will fall short of actual individuality and so be abstract. $^{20}$ This is our sense three, abruptness, which we can now explain. Since the description or analysis of any concrete individual is always finite, at some point it is discontinuous. It breaks off abruptly with a determination or characteristic that is not further qualified in the description, even though that quality in the individual is in fact still more nuanced, indeed, infinitely more nuanced, than the description allows.

One of Whitehead's boldest and most ingenious claims is that finite abstractive hierarchies are not artifacts of our descriptions, but rather exist independently of consciousness. Although they do play an important role as the content of all conscious mentation, they are also factors in the constitution of things that do not think and need not be thought about. Things that fall short of actual individuality exist and play a critical role in the make-up of what is fully actual and individual, whether or not it is a conscious or even a living type of individual. And this yields us our fifth sense of abstractness, for if the abstract "really exists" and contributes to the concreteness of things, then any ontology limiting itself to what is concrete in the more conventional sense is ipso facto abstract. ${ }^{21}$ Such an ontology would fail on its own terms to be an ontology of the concrete if the concrete is itself actually informed by a constitutive relevance of the 
abstract. For example, a description of a human being that ignored values and goals would obviously be far more abstract than one that took them into account. This constitutive relevance of the abstract is what Whitehead calls mentality. But he means by mentality something relevant to the constitution of all beings, not just conscious ones. Mentality, in other words, is broader than consciousness, and whether it is conscious or not, it presupposes rather than generates its abstract objects, which are finitely complex sets of eternal objects. It is best to take this provocative proposition in two steps: first, the Platonistic claim that thought presupposes rather than generates its abstract objects; second, the peculiarly Whiteheadian claim that these objects contribute to the specificity of more than just conscious thinking.

(1) Whitehead's belief in the ontological autonomy of abstractions in senses one, two, and three has obvious affinities with the so-called Platonism of such nineteenth century thinkers as Bolzano, Lotze, Frege, and Meinong, who were all agreed that non-actual or incompletely individuated things can and do have some kind of being. ${ }^{22}$ In fact, Meinong's non-existent objects offer a particularly good example of the abruptness of a finitely complex set of eternal objects. The golden mountain has exactly two properties: it is golden and it is a mountain. It makes no sense to ask what the weather is like on the golden mountain unless we stipulate that, too. But a real mountain will have properties we have not stipulated, but can discover - infinitely many of them. Thus, on a real mountain there will be weather, an average annual rainfall, a standard deviation to the average annual rainfall, a change in the standard deviation over periods of time, and so on and so on with qualifications and refinements indefinitely. Thus, although every description of the mountain is finite, it is a description of a real mountain only because the description could be continued indefinitely. By contrast, whenever we think about something unreal (or not yet real, like a goal), we are able to capture what we mean by a description that stops satisfactorily with a finite amount of detail. It is easy to see that everything we normally think of as physical proffers material for an interminable description, while everything we normally think of as mental, such as concepts, wishes, theories, fantasies, or descriptions themselves, is (and must be) finite and abrupt in this way. The idea that finitude of content characterizes the mental thus accords with our experience. But the usual assumption is that this finitude of content is an artifact of consciousness. What the logical Platonists of the nineteenth century claimed was that these mental objects did not depend on thought, but on the contrary that thought depended on the self-sufficiency of these objects, which, even if they do not and indeed cannot exist in the most eminent way, nevertheless have some kind of originary presence. 
(2) But for all of the thinkers mentioned, their ideal forms (or "nonpsychological concepts" or "pure objects") tend to be conceived as purely logical entities, and as such they are physically and metaphysically inert, relevant only to cognition. Whitehead, on the other hand, wants to solve the problem that Aristotle had already exposed in Plato's original version of the theory of forms: how can they ever be causes of anything if they are so ethereal and derealized as to be inert cognita? Whitehead's metaphysics of process is meant to explain how finite abstractive hierarchies - independent of their being excogitated by conscious subjects - affect the outcome of events in nature. Whitehead believes it is the abruptness of finitely complex eternal objects that allows for a discontinuity of otherwise deterministic processes and explains how the irruption of something genuinely new into the world is possible. The constitutive relevance of the abstract to the concrete creates a leeway for unpredictable development.

Whitehead may be the only philosopher who has offered a purely logical definition of the mental. "This breaking off from an actual illimitability is what in any occasion marks off that which is termed mental from that which belongs to the physical event to which the mental functioning is referred." ${ }^{23}$ Mentality is defined by the abruptness of a finite abstractive hierarchy, which not only accords with our own experience of mentality, but also gives us a general criterion for mentality that allows us to generalize it to "inanimate" things without falling prey to animism and anthropomorphism. Mentality is the discontinuity of natural processes that makes room for spontaneity and novelty in the outcome. Table II summarizes our results so far.

We can now understand the important conceptual differences between the second and third types of abstractness and finally return to the two types of transcendence (which I have suggested correspond respectively to the second and third kinds of abstractness). Universals are transcendent in the second sense of abstractness (first sense of transcendence) because they can be multiply instantiated. Each universal thus transcends any particular instance the way the possible transcends the actual. But universals are transcendent in the third sense of abstractness (second sense of transcendence) inasmuch as they fall short of a complete description of the qualitative specificity of an individual, which in an important sense they always do. For no matter how detailed, no description employing an inventory of concepts finitely will ever be sufficiently nuanced to be able to pick out an actual individual uniquely. The description will be applicable to multiple individuals (and thus transcend them) not so much because of an inherent possibility of multiple instantiation, but because it leaves out 
distinguishing nuances. It will therefore be transcendent in a sense clearly distinct from the former.

Table II

\begin{tabular}{|c|c|c|}
\hline PU (Wiehl) & PK (Wiehl) & SMW (Whitehead) \\
\hline & $\begin{array}{l}\text { Abstraction Type } 1 \\
\text { (EO apart from its } \\
\text { Relationships to All } \\
\text { Other Eos) }\end{array}$ & $\begin{array}{c}\text { Individual Essence of an Eternal } \\
\text { Object } \\
\text { (SMW 159) }\end{array}$ \\
\hline $\begin{array}{l}\text { Transcendence of } \\
\text { Universals-Type } 1\end{array}$ & $\begin{array}{l}\text { Abstraction Type } 2 \\
\text { (EO as Possibility } \\
\text { apart from Its } \\
\text { Realizations in } \\
\text { Actual Instances) }\end{array}$ & $\begin{array}{c}\text { Eternal Object as a Pure Possibility for } \\
\text { Instantiation } \\
\text { (SMW 158) }\end{array}$ \\
\hline \multirow[t]{3}{*}{$\begin{array}{l}\text { Transcendence of } \\
\text { Universals-Type } 2\end{array}$} & $\begin{array}{l}\text { Abstraction Type } 3 \\
\text { (EO as Unspecific } \\
\text { Determination apart } \\
\text { from Individuating } \\
\text { Factors) }\end{array}$ & $\begin{array}{c}\text { Any Finitely Complex Eternal Object } \\
\text { (SMW 171) }\end{array}$ \\
\hline & & $\begin{array}{c}\text { Actual Infinity of an Infinitely Complex } \\
\text { Eternal Object } \\
\text { (Greatest Abstraction from Possibility: } \\
\text { Concrete Individuality) } \\
\text { (SMW 169ff.) }\end{array}$ \\
\hline & & $\begin{array}{l}\text { Real Individuals Considered Physically } \\
\text { (Apart from their } \\
\text { Mentality/Spontaneity) } \\
\text { (SMW 170) }\end{array}$ \\
\hline
\end{tabular}

It is important to see that these two kinds of transcendence can, but need not, coincide. This will depend on one's theory of individuation, which brings us to the nerve of all these distinctions. The divisive question will be: can something be abstract in sense two (capable of multiple instantiation) without being abstract in sense three (an incomplete description)? Depending on how she understands individuation, a philosopher will have a different understanding of abstractness and universality, and she will tend to privilege one or another of the 
discriminated senses of abstractness accordingly. But the converse is just as true: commitment to the priority of one or the other senses of abstractness will largely determine one's theory of individuation.

\subsection{Universality and the First Type of Transcendence}

Defining universality primarily in terms of the possibility of multiple instantiation suggests that universals become instantiated by becoming the attributes of a thing, which instantiates and thus individuates them. It is crucially important to see that the thing individuates the type without further specifying it, for any specification would ipso facto belong to the type and be capable of multiple instantiation! This implies that what universals lack is not (necessarily) adequate specificity, but (necessarily) the indefinable quality Scotus called haecceitas.

Haecceitas is the quality of unique singularity that makes a thing capable of being the ultimate referent of ostensive indication: this one as opposed to that one, where both are identical in type. This possibility means that individuality is somehow something more than extreme specificity of type. Individuality must involve something sui generis and indefinable: a discriminated singularity beyond anything that could be specified employing nothing but abstract concepts and universal descriptors. Consequently, if we restrict ourselves to understanding universality according to the first type of transcendence, there would be no in-principle reason why a complete description of an individual thing by a finite set of universal predicates should be impossible. Since individuality in this case would not depend on infinite nuance, the lack of infinite nuance implied by the possibility of a complete but finite description would not be at odds with the requirement that what exists be fully individuated. The description would not lack adequate nuance, but only the primitive, indefinable quality of the thing's haecceitas that no description can capture. Furthermore, even though it was a complete description of an individual, it would still be capable of multiple instantiations: two individuals could be identical in all respects and still be different individuals simply because they were different things, differing only in virtue of their respective haecceitas. And last but not least, on this theory of individuation there would be no inprinciple reason why even an infinite abstractive hierarchy must uniquely identify an individual. Decoupling specificity from individuality not only means that individuality does not depend on infinite nuance (as its necessary and sufficient condition), but also that infinite nuance fails to 
entail individuality even in the manner of a sufficient (but not necessary) condition. All this means is that an infinite abstractive hierarchy would in and of itself still lack haecceitas. Consequently, there would be no reason why the same infinite abstractive hierarchy could not be multiply instantiated. Multiple individuals could have the same infinitely nuanced specificity and would differ only numerically. Individuality would thus involve a discriminated singularity beyond what could be specified even in an infinite description. On this understanding of universality, something can be abstract in sense two (capable of multiple instantiation) without being abstract in sense three (incomplete), but not vice versa. Sense two thus becomes the fundamental sense that will define what the transcendence of universals essentially means: lack of haecceitas.

We saw that defining universality primarily in terms of the possibility of multiple instantiation suggests that individuation happens when universals become instantiated as attributes of a thing. Consequently, this view of universality leads quite naturally to the idea that haecceitas is something that belongs exclusively and inalienably to the thing-substrate. Other interpretations of haecceitas are of course possible. Some will be considered later in this paper: haecceitas as relative or absolute space-time location, relative position in (or in relation to something in) the immediately experienced intuitive manifold, indication by token-reflexive reference. However, since these interpretations have a hard time expressing what it is that does the instantiating in the token-type relationship, they are intuitively less obvious than the thing-theory of individuation, for which a "thing" is simply the requisite vehicle for instantiation. The interpretation of individuation most readily suggested by the first kind of transcendence is therefore the Aristotelian one, which associates individuation with an ineffable thisness of things. Nevertheless, multiple instantiation of the same type remains possible even if we decide to get rid of "things" and reinterpret haecceitas as, say, relative or absolute space-time location or token-reflexive indication within a field of immediate acquaintance.

Discussion of these more complicated options is reserved for subsequent parts of this paper. But a general reservation about the singularity-beyondspecificity view of individuation belongs here. A pre-requisite of this view of individuation seems to be that we allow individuals instantiating the same type to differ in "accidental" respects and count among the accidents their relational properties inter se, such as their relative space-time location. Otherwise we would indeed be unable to discriminate them and thus unable to identify them (as being distinct but "the same"). This consideration suggests that the various theories of haecceitas (unique 
thinghood, space-time locus, object of token-reflexive reference) are more intimately connected than might have seemed at first glance.

\subsection{Universality and the Second Kind of Transcendence}

Defining universality in terms of the shortfall of any finite description vis$\grave{a}$-vis the richness of the individual suggests that a complete description, if it could be achieved, would not lack individuality and would thus be ipso facto incapable of multiple instantiation. But a complete description cannot, on this telling, be achieved because individuality is the result of a synthesis of universals that is infinitely complex or nuanced (an infinite abstractive hierarchy). On this view of individuation, multiple identical individuals would be impossible. All individuals would have to be different in specie even though the difference could not be specified in any finite description. Haecceitas as an indefinable formal addition to things would be superfluous to their individuality. The individual would be unique precisely and only because it is infinitely complex. It would differ in specie from every other individual simply because there would be no other effective principle of numerical individuation than specificity. On this understanding of universality, nothing can be abstract in sense two without being abstract in sense three. Indeed, it can be abstract in sense two only because it is abstract in sense three. Sense three thus becomes the fundamental one that defines what the transcendence of universals essentially means: lack of complete specificity.

If this reading of the two kinds of transcendence is correct, then we are finally in a position to understand one of the principal themes in Professor Wiehl's paper: how each meaning of transcendence is differently biased in regard to the primacy of things and processes. Privileging the first meaning of transcendence leads to a thing ontology and an Aristotelian theory of individuation. On this account, formally identical individuals are possible: two things can be the same in all specifics, and yet numerically distinct simply because they are numerically distinct things. Privileging the second meaning of transcendence leads away from a thing ontology to an understanding of the individual as an unrepeatable singularity (an event) and hence to a radical process ontology and a Leibnizian theory of individuation. On this account, instantiation would not require a substrate, such as things or "matter" or intuition or space-time. Instantiation would coincide with the logical fact of extreme specificity. But by the same token, instantiation would be incapable of adding to type-specification any further 
degree of individuation. Multiple identical individuals would therefore be impossible. All individuals would be different in type.

Here is perhaps the place to interrogate the mischief-making Principle of the Identity of Indiscernibles. Let's bracket for a moment the question of finite versus infinite descriptions and focus simply on the idea of multiple individuals with identical descriptions. Surely the Principle of the Identity of Indiscernibles holds in a very basic sense that if there were absolutely no differences between two individuals then they would indeed be the same individual. But if that were the last word on the matter, then the question we are asking - can numerically distinct individuals be the same?-would be senseless. The short answer would be: of course not, otherwise they would not be numerically distinct. Now this short answer may seem to be the very claim of the Principle of the Identity of Indiscernibles, but in fact it is not. The short answer, because it takes itself to be a tautology and hence self-evident, denies the meaningfulness of the question, which, it assumes, is asking about the possibility of something impossible, the possibility, namely, of a contradiction. But the Principle of the Identity of Indiscernibles - while it also gives a negative answer to the question can there be identical individuals? - is nevertheless giving a very different answer than the short one, for it gives a negative answer to our question in a context where the question itself is assumed to be meaningful. The Principle of the Identity of Indiscernibles, in other words, does not take itself to be trivially true, but to be a strong metaphysical claim, the falsity of which is not logically impossible. An easy way to illustrate this difference is to point out that the short answer has no consequences, while Leibniz famously employed his principle to prove the unreality of space.

The Principle of the Identity of Indiscernibles is therefore a principle of strong metaphysical consequence, and both its truth and its falsity have important implications that would, in the case that obtains, constitute $a$ priori knowledge about the world. Thus, to understand the Principle of the Identity of Indiscernibles, we must understand the conditions under which it is meaningful to ask if two things can be the same. We already have what we need to do this. I noted above that a pre-requisite of the singularitybeyond-specificity view of individuation (such as the haecceitas theory) seems to be that we allow "identical" individuals to differ in "accidental" respects. Otherwise there could be no sense in asking if things that are different (different enough to count) are "the same," and nothing could be considered the same as anything other than itself. This observation reveals what we are looking for. There are specifically two assumptions that make the sameness of discernibles a meaningful question and the Principle of the Identity of Indiscernibles, as well as its denial, a matter of strong 
metaphysical consequence. First, the idea (or possibility) of multiple instantiation depends on a distinction between accidental and essential properties or at least between absolute and relative ones. If all predicates were on the same footing, it would be impossible to see how we could ever say two "distinct" items were the "same." What we mean when we say this is ostensibly that they differ only in "accidental" respects. And yet these accidental differences seem to be essential to the possibility of a plurality of "identical" instances! Perhaps, however, they are essential only for our recognition of such individuals. This consideration points up the second important assumption in play here. The idea (or possibility) of multiple instantiation presupposes a certainty that accidental or relative predicates, however necessary they may be for our a posteriori discrimination of otherwise identical individuals, are unable to individuate them. If we assume otherwise, the Principle of the Identity of Indiscernibles (or its denial) ceases to be a principle of strong consequence that tells us something a priori about all the individuals in the world (namely: that they are/are not all different in specie; that they do/do not possess a singularity beyond specificity) and reverts to being an undeniable tautology of no philosophical value.

It is significant that endorsement of these two assumptions characterizes the positions of both Aristotle and Leibniz, despite the fact that it leads them to opposite conclusions about individuation. In both cases, however, it leads to strong a priori conclusions about the nature of individuals. Assuming the Principle of the Identity of Indiscernibles, Leibniz argues: because space (i.e., relative predicates) cannot individuate things, their relative difference in space (their presence at different locations) presupposes that they are already differently individuated in their absolute properties. In other words, the Principle of the Identity of Indiscernibles is able to prove the unreality, superfluousness, or derivativeness of any discriminating predicates over which it is not defined in the first place. Leibniz's conclusion is that all individuating differences (any differences resulting in the possibility of discrimination) have to be essential or derived from essential differences. Since spatial location is a relative difference, it must be derived from absolute differences. ${ }^{24}$

Aristotle begins in a similar place, but because he employs a different principle, he arrives at a different place than Leibniz. The principle Aristotle assumes is the following: what is essential is precisely what things of the same natural kind ${ }^{25}$ have in common. He thus argues: since (a) accidents cannot individuate things and (b) what is essential is precisely what things of the same natural kind have in common, something else, which is sui generis, neither accidental nor essential, must be at work in 
individuation. For Aristotle, this is the actuality of the essence, which is not a universal (a commonality) any more than it is an accidental singularity. This theory is remarkable, for at the same time that it explains individuality without recourse to accidental predicates, it allows individuals to be distinct and yet essentially identical. In other words, demoting discriminating predicates to the status of accidents incapable of individuating a thing and incapable of derivation from what individuates it abrogates the identity of indiscernibles in principle. Aristotle and Leibniz therefore agree (a) on a distinction between relative and absolute predicates and (b) that relative predicates cannot individuate anything. For Aristotle this means that the Principle of the Identity of Indiscernibles is just not true. For Leibniz it means that relative differences must be the external reflection of absolute ones so that the validity of the Principle of the Identity of Indiscernibles is preserved. An important variation on the arguments we are considering, which forfeits any ability to draw a priori conclusions from the Principle of the Identity of Indiscernibles, holds that individuals can be essentially the same (like Aristotle and unlike Leibniz), but that accidents are after all enough to individuate them inter se (contrary to both Aristotle and Leibniz). This is a not uncommon position in the history of philosophy. It appears to be the teaching of many Scholastics and of Aquinas in particular.

Now let us go a step further and examine what happens if we abstain from making such a predicate-type distinction as essential versus accidental or absolute versus relative. For one thing, as noted above, the Principle of the Identity of Indiscernibles becomes an insignificant tautology. All things will be the same thing or differ in some predicate, end of story. But even if we envision a world in which all predicates are of a homogenous type, we can still draw an ideal contrast and ask if the predicates in this world are all essential (or all like the ones we were calling essential) or all accidental (or all like the ones we were calling accidental). The thesis "all differences among individuals are accidental differences (i.e., all properties are accidents; there are no "real" essences) should perhaps make us think of Ockham and the Nominalists. The thesis "all differences among individuals are essential differences" (i.e., there are no "accidents;" all properties are essential to what a thing is) should perhaps make us think of the Stoics and of Spinoza.

We can summarize our results by reviewing the different kinds of abstractness and seeing how all but the last involve a kind of transcendence. In sense (1) each eternal object is abstract insofar as it transcends the others in its individual essence. In sense (2) each eternal object is abstract by virtue of its inherent possibility for multiple 
instantiation. It thus transcends each and every actual instance. In sense (3) any finite complex of eternal objects is abstract simply because it is finite: everything fully concretely real is infinitely specific. The finitely complex eternal object thus transcends individuals the same way the genus transcends the species. In sense (4) the concrete is abstract insofar as it is the extreme of abstraction from possibility. Since this coincides with an infinite specificity, the adequate description of which would, if we only could execute it, never break off at any last specification, it transcends any description the way the infinite transcends the finite. In sense (5) the physical is abstract if taken apart from the mental. The reflections that led to this last conclusion can be recapitulated as follows. In and of itself, the finite abstractive hierarchy lacks any concreteness. But it is nevertheless relevant to the process by which things become concrete. As mentality, this relevance becomes causally efficacious, exercising a force of innovation discontinuous with what already exists. It thus contributes something to the fullness of a thing's concretion, and nothing can be considered fully concrete in abstraction from the forms of abstractness that have informed its coming to be. It is this kind of consideration that allows Whitehead to see in materialism an entirely abstract doctrine.

\section{Two Ways of Distinguishing Concepts and Intuition}

A distinction between different faculties (or modalities) of cognition in terms of a fundamental polarity or positive/privative contrast is almost universal in the history of philosophy. But how the contrast operates has been understood in two very different ways. The following table of contrasts associated with traditional theories of cognition will illustrate the common ground, which evidently goes beyond a mere pattern of polar contrasts to include a similarity in the content of what functions contrastively. The table draws freely from the history of philosophy and is not meant to be either exhaustive or systematic. A few examples from each period suffice to indicate a large pattern of agreement. Consider the following spectrum of oppositions that runs the gamut from Parmenides to Frege:

Table III

\begin{tabular}{|c|c|}
\hline $\begin{array}{c}\text { doxa } \\
\text { aisthesis }\end{array}$ & aletheia \\
noesis \\
\hline
\end{tabular}




\begin{tabular}{|c|c|}
\hline katalepsis & prolepsis/ennoia \\
species impressa & species expressa \\
sensation & intellection \\
perception & understanding \\
intuition & concept \\
sensibility & understanding \\
receptivity & spontaneity \\
intuition & signification \\
object & concept \\
\hline
\end{tabular}

Similarly, opposite qualifications attach to the respective modalities (or to their activities or contents or objects). Here are a few of the familiar ones (there is no ordered, one-to-one correspondence between the items in the preceding and following lists; the correspondence is only between the groups):

Table IV

\begin{tabular}{|c|c|}
\hline visible & invisible \\
unbounded & bounded \\
relative & absolute \\
fleeting & remaining \\
non-intelligible & intelligible \\
deceptive & faithful \\
particular & universal \\
concrete & abstract \\
passive & active \\
given & made \\
confused & distinct \\
sensuous (full) & non-sensuous (empty) \\
immediate & mediate \\
manifold & one \\
non-discursive & discursive \\
continuous (dense) & discrete \\
analog & digital \\
\hline
\end{tabular}


To these catalogs we must add Whitehead's contrast: infinite versus finite abstractive hierarchy.

Now, however difficult it may be to agree on what the common denominator is in each column, I doubt there will be any disagreement that the terms have in each case been assigned to the appropriate side. The members of each group have a strong family resemblance to one another, despite the obvious fact that they do not line up in terms of relative value: the true or more true or truth-conferring term of the contrast switches back and forth for different pairs. I illustrate this by assigning each pair in Table III to one or another philosopher or school closely associated with that particular way of drawing the contrast and giving an asterisk to the term privileged by that philosopher or school:

Table V

\begin{tabular}{|c|c|c|c|}
\hline \multirow{5}{*}{$\begin{array}{l}\text { Ancients/ } \\
\text { Medievals }\end{array}$} & Parmenides & doxa & aletheia* \\
\hline & Plato/Aristoteles & aisthesis & noesis* \\
\hline & Stoics & katalepsis* & prolepsis/ennoia \\
\hline & Neo-Platonists & sensation & intellection* \\
\hline & Scholastics & species impressa & species expressa* \\
\hline \multirow{5}{*}{ Moderns } & Locke & perception* & understanding \\
\hline & Leibniz & perception & understanding* \\
\hline & Kant/Neo-Kantians & $\begin{array}{l}\text { intuition* } \\
\text { sensibility* } \\
\text { receptivity* }\end{array}$ & $\begin{array}{l}\text { concept } \\
\text { understanding } \\
\text { spontaneity }\end{array}$ \\
\hline & Husserl & intuition* & signification \\
\hline & Frege & object* & concept \\
\hline
\end{tabular}

There are many peculiarities and much to think about in this schema, but I want to highlight only one thing. While a division of cognitive modalities made by contrasting the immediate givenness of something concrete and qualitatively dense with the remove of something intangible and counteroperating from within remains constant throughout the history we are looking at, what is considered to be the ultimate source of validation migrates back and forth. The reason for this is rooted in a deeper 
disagreement about the way the terms of each couplet are opposed. The critical question over which the philosophers divide is whether the two modes of cognition know different objects or the same objects in different ways. To say with Whitehead, for example, that concepts will never capture the whole content of intuition implies that capturing the content of intuition is what concepts try to do and that, in fact, they succeed at capturing at least some of it. This establishes a definite idea of the relation between concepts and intuition. It implies that concepts and intuition deal with the same objects, but in different ways. Intuition contains the fullness of the object. Concepts do not. Conception is an economical but intrinsically deficient way to know something about the same object we do or can intuit.

This view of the relationship between concept and intuition is the one usually thought of as modern and explains why for most of the modern figures listed the source of validation falls in the left-hand column. The contrary view, that concept and intuition have different objects, is the view usually thought of as ancient and, as we shall see, explains why for most of the ancient and medieval figures listed the source of validation falls in the right-hand column. Of course there are important exceptions to this rule on both sides of the supposed ancient/modern split.

The view typically associated with Greek antiquity is that the aistheton and the noeton are different kinds of objects. The intelligible and the sensible constitute separate worlds. This is indeed the view of Parmenides, Plato, the neo-Platonists, and-with important qualifications-Aristotle. Different cognitive modalities, like aisthesis, doxa, dianoia, and noesis, each have their own proper objects. This is the point of Plato's divided line, which is a graded classification of objects. The most noble kind of objects top the line and the shabbiest kind anchor it. A separate cognitive modality is required (and so postulated without further ado) for each class of objects. Since these modalities differ in value depending on the value of their respective objects, the divided line does indirectly become a graded classification of cognitive modalities, but these are not valued as better and worse apprehensions of the same things, but as the cognitive correlatives of better and worse types of objects.

Of course there are ontological relations of dependency and derivation among the different classes of objects. According to the divided line: images depend on things; things depend on the mathemata; and the mathemata depend on the forms. In general, the sensible world depends on the intelligible world as an image upon its original. This fact can be interpreted to mean that knowing one class of objects involves knowing another class eminently or deficiently. This was a favorite tack of neo- 
Platonism-perceiving appearances is a deficient way of knowing the being upon which they depend; having intellection of being is an eminent way of knowing the appearances that depend on it. But this is only because of the objective relationships that exist among the various classes of objects. It is the interrelation of the objects, not the variable efficacy of cognition that is responsible for the availability of an object in more and less adequate ways. Strictly speaking, each mode of cognition has its separate objects, which are not properly available to the other modes. What Plato and Aristotle called "true opinion" offers a clear-cut example of this situation. True opinion is not a deficient way of knowing something that could have been proved; it is the proper way to know something contingent that cannot be proved. ${ }^{26}$ To the classical Greek way of thinking typified by Parmenides, Plato, and (with qualifications) Aristotle, to say nothing of its neo-Platonic revival in late antiquity and the early Renaissance, it is the being of the object that is eminent or deficient, not the way it is known. Perception is inferior to intellection not because it is a deficient mode of cognition, but because it targets a class of objects deficient in being.

Aristotle does not uphold this view in all respects. For Aristotle, knowledge of separate substances and first principles is noetic in a way that contrasts with aisthesis in terms of their respective objects. But in the allimportant case of composite substances it turns out that sense perception and intellection are both directed at the same thing, just knowing it in different ways. For if we were to say that the composite is only sensible and cannot be known, that only the form is known, making primary and secondary ousia separate objects, we would do violence to Aristotle's fundamental intent. However different, primary and secondary ousia are also one and the same (in a way that we can recognize as peculiarly Aristotelian even if it is exasperatingly difficult to elucidate). For one thing, the form is not a separate and distinct model upon which the composite is based, but its own being and essence. On the other hand, it is not an accident that the form is the form of a composite. Such a form is, accordingly, actual only insofar as it is actualizing the composite (which it perforce is always doing). To grasp such a form is thus to know something perceived, not something separate.

Granted that in the case of composites intellection and perception are both directed at the same thing, the question of which mode is eminent and which is deficient turns out to be frustratingly tricky. It may seem obvious that thought is eminent because it grasps the essence, but the essence is actual only insofar as it is actualizing the sensible individual. Parallel to Aristotle's systematic equivocations about the relative priority (as well as the identity and difference) of primary and secondary ousia we therefore 
find an ambivalence about which mode of cognition is eminent and which is deficient. On the one hand, since what sense-perception grasps are accidents, not essences, it is obviously deficient. Accordingly, there are many passages where Aristotle presents thought as the eminent mode of cognition vis-à-vis composite substances. ${ }^{27}$ But insofar as thought grasps only universals, it, too, is deficient. The real is actually individual and concrete, and to know it means to grasp it in its actuality. ${ }^{28}$ Accordingly, there are decisive passages where Aristotle clearly gives privilege to aisthesis! $!^{29}$ Of course this should not be misconstrued as an incipient nominalism. Aristotle never identified individuality with the sum of contingent differences we could perceive between one thing and others. As I will discuss in the next part, Aristotle always thought of individuality as the unique tokening of the essence, which implies but does not depend on the presence of sensible accidents. But this does make the token, not the essence, the object of eminent cognition. In fact, what Aristotle appears to envision is a situation where eminent cognition is flanked by opposing deficiencies: sense-perception insofar as it only grasps accidents (aisthesis) and thought insofar as it only grasps universals (dianoia), between which we find noesis, a mode of cognition that grasps what is essential (like dianoia), but at the same time targets the concrete (like aisthesis). What marks Aristotle's approach as fundamentally classical in its outlook is that noesis (eminent cognition) is always more thought-like than perceptionlike, whether its objects are separate or composite substances, while aisthesis, even when it fronts for noesis as the eminent mode of cognition vis-à-vis the sensible composite, is deficient in comparison with cognition of separate substances: substances that are sensible are ipso facto less knowable than those that are not. Hence, Plato's graded ontology of beings is indirectly preserved: the availability of some substances to a deficient mode of cognition (whether we construe it as aisthesis or dianoia or both) is the result of their own deficiency of being. Intimately connected with this - its flip side - is Aristotle's refusal to abandon the idea of secondary ousia altogether. As long as secondary ousia is an essence rather than an abstraction, it will be necessary to seek eminent cognition of the individual in something ultimately thought-like.

As usual, it is the Stoics who seem to have been primarily responsible for a break with classical attitudes. According to the Stoics, who were strict materialists, there is no intelligible world, no such thing as separate substances. Only sensible individuals are real, and they inhabit a world in which the Principle of the Identity of Indiscernibles holds absolutely. Consequently, true knowledge must be the grasp of an individual thing's unmistakable uniqueness. The Stoics are thereby compelled to make two critical changes to the epistemology they inherited. First, because there are 
no separate intelligible objects, they universalize what for Aristotle was a principle of limited validity: the notion that perception and thought can be directed at the same object. Secondly, because there is no place for essences in this scheme, they invert the order of importance classically ascribed to thought and perception. Perception is the eminent mode (always), while intellection is the deficient one (always). Intellection is the deficient mode because for the Stoics it is nothing more than deficient perception: sensible ideation that stops short of being able to pick out something in the world uniquely. What Aristotle called an essence is simply a description that applies equally to multiple individuals because it fails to completely describe any of them. This inversion of the classical order is reflected in the table above, where the Stoic katalepsis (the "cognitive impression" that captures a thing in its unmistakable singularity) falls on the same side as Parmenides' doxa, and the ficta of their prolepseis and ennoiai (i.e., general concepts and abstract notions) fall on the same side as Parmenides' truth. The Hellenistic perspective is a complete reversal of the classical one:

Table VI

\begin{tabular}{|c|c|c|}
\hline & Sensible & Intelligible \\
\hline Parmenides, Plato & Doxa & Truth \\
\hline Stoics, Epicureans & Truth & Fictions \\
\hline
\end{tabular}

The skeptical reader can verify that the Stoics' katalepsis has been lodged in the proper column of Table III by tracking its crucial properties, which fall in the left-hand column of Table IV. The kataleptic impression is sensuous, immediate, given (passively received), concrete, and particular, even if it is not unbounded, deceptive, or confused.

The Stoic view that thought is a deficient grasp of the same object that is fully available to perception takes hold in Hellenistic thinking, propounded mostly by philosophers, but it becomes strikingly evident in the epistemological ideas of the great practicing scientists of the Roman period, Ptolemy $^{30}$ and Galen. ${ }^{31}$ This is the view taken up again in the later Renaissance, indebted as it was to the recovery of Hellenistic ideas. Finally, Kant is the one who puts into a kind of canonical form the idea that concepts are a finite and penurious way to designate indirectly what intuition gives us immediately in inexhaustible plenitude. This idea continues to play a crucial role into the twentieth century: in neoKantianism and in Husserl's phenomenology, for example. ${ }^{32}$ In fact, when Whitehead says that it is impossible to complete the description of an 
actual individual by means of concepts, he reveals his extraordinary proximity to his German contemporaries, Ernst Cassirer and Heinrich Rickert, whose neo-Kantian philosophy revolved around the importance of this insight. ${ }^{33}$

But just as views in antiquity were not homogenous, views in the modern period are not either. Nevertheless, it was not until the extraordinary developments of mathematics in the nineteenth century that the StoicKantian viewpoint encountered real peril. When mathematics moves beyond Euclidean geometry and the theory of real numbers it becomes impossible to see mathematical concepts as attenuated ways of knowing the sensible world and a return to Platonism becomes hard to avoid. Many accepted this; many did not. The theory of logic known as Intuitionism appears to be a way of embracing the counter-intuitive advances of mathematics without giving up the Stoic-Kantian view of thought as beholden to intuition.

This discussion can now be harvested for its bearing on individuation. If conceptual thought is merely a deficient approach to the intuitive object, then we should expect to find individuals only in intuition. But if conceptual thought has its own objects, there is no reason why we should not be able to find individuals in the intelligible world as well. Another possibility is the one that Leibniz explores: that intuition is merely a deficient approach to an intelligible individual, whereby we should expect to find individuals only in the intelligible world. That true individuality is intelligible, not sensible, is of course the position of the classical Greek philosophers, but they got there in a very different way. They thought that sense perception knew an object deficient in true individuality, not that sense perception was deficient in grasping the true individuality of its object. But either way, the fact remains that if any individuals can be found in the intelligible world, then there is no reason to think that what individuates even a sensible individual is itself necessarily something peculiar (or peculiarly available) to intuition. The two views of the relation between concepts and intuition therefore imply two different views about individuation, to which I now turn.

\section{Peculiarities and Problems of the Traditional Theories of Individuation}

Traditionally, there have been two basic theories of individuation. One is the theory we find in Aristotle's account of composite (sensible) 
substances, in Duns Scotus, or in Kant: universals can never yield individuality; individuality is a primitive and irreducible principle, unique to and constitutive of each thing (like the thisness of Aristotle's tode ti, or Scotus' haecceitas, or immediate givenness within the space-time manifold of intuition). For convenience, I will call this the intuitionist theory of individuation (not to be confused with the intuitionist theory of logic). The other theory is the one we find in the Stoics, in Leibniz, in Aristotle's theory of separate substances, or in Scholastic angelology: all things differ in specie; nothing differs in number only; individuals are simply the infimae species (the last or most specific species), while universals are the next up species and all the higher genera. ${ }^{34}$ For convenience I will call this the logicist theory of individuation. (The placement of the Stoics in this classification is peculiar: here I group them with logicists even though in the previous section I identified them as intuitionists. How they can be metaphysical logicists and epistemological intuitionists is something that will concern us later.) I set the stage for comparing these two paradigms of individuation by reviewing Plato's theory of individuation in the Timaeus. Then I look at the intuitionistic and the logicist theories in that order.

\subsection{Plato's Theory of Individuation in the "Timaeus"}

The first formal attempt at a theory of individuation is to be found in Plato's Timeaus. Plato postulated the forms to explain why things are always of a certain sort such that the question what is it? always makes sense, even if we can't always answer it. But forms can't provide an answer to the other question so basic that it always makes sense to ask it: does such a thing exist? In the Timeaus, Plato proposed the amorphous spatial matrix he called the Receptacle as the basis for existence: a thing of such and such a kind exists when the form of such a thing is realized in the medium of the Receptacle. The Receptacle is simply postulated as something that makes such tokening (instantiation) possible, just as the bronze is what makes it possible for the sculptor to realize his design. Plato concedes the ad hoc character of this postulate when he says that we arrive at the notion of the Receptacle through a form of "bastard reasoning." He knows, in other words, that strictly speaking it would be a fallacy to argue: something such as the Receptacle would explain the difference between tokens and their types; since there is such a difference, the Receptacle must exist. Nevertheless, he seems to regard the Receptacle as the only possible way to explain the difference between tokens and their types, which makes his bastard reasoning not a fallacy, but the first clear example of 
methodologically self-conscious transcendental argument in western philosophy. The Receptacle is the condition of the possibility of existence (that a thing is) as distinct from quiddity (what a thing is).

However, at the same time the Receptacle explains something else. It explains numerical individuation: how there can be more than one thing of a given type. An easier way to explain multiplicity would have been to say that no two things are really identical. Such a position had already been adopted by Anaxagoras and articulated very clearly by Diogenes of Apollonia. ${ }^{35}$ But Plato is at pains to pursue another path. He denies the Receptacle any character of its own so that it can realize the forms perfectly without distortion. There is, consequently, nothing to stop it from realizing the exact same form arbitrarily many times. The Receptacle has no effect other than to allow for a token-type distinction and a multiplicity of tokens. The principle Leibniz called the Identity of Indiscernibles has no validity in the cosmology of the Timaeus. According to Timaeus" "likely story," what we find at the most elemental level of physics is a limited variety of regular geometrical shapes, each of which is identically instantiated countlessly many times. Since the Receptacle exercises no resistance to the forms realized in it, the elementary particles of air, earth, fire, and water are not morphological approximations to, but perfect realizations of the regular solids. They are, moreover, nothing but these geometrical shapes. They have no other properties, and all their phenomenal properties are supposedly reducible to geometrical ones. The fact, for example, that things in our ordinary experience are subject to change and are always imperfect realizations of "what they are" is deduced from the geometrical properties of the elements, which ultimately are perfect and unchanging (the triangles, namely, of which the solids are composed). It is a matter of simple necessity that things composed of such elements will be unstable and subject to motion, unrest, and corruption in mathematically determined ways depending on the mode of composition. The pure receptivity of the Receptacle is, in other words, conceptually designed for the purpose of reducing everything without residue to form and the formal relations of forms.

This reduction to form creates an air of paradox that is difficult to avoid in any theory of individuation allowing for multiple identical individuals. The individuals of the Timaeus are complexes of nothing but universals, so what makes them existing individuals rather than unrealized forms? Clearly the Receptacle contributes everything to this difference, and yet it is critical that it contribute absolutely nothing! Anything positive it contributed to the differentiation of identical individuals would ipso facto make them nonidentical and should really be counted as a formal difference. This 
generates the problem that Aristotle saw with Plato's theory of individuation. Even though he believes in the multiple instantiation of something formally identical and postulated the Receptacle to explain this, Plato has failed to say why anything is concrete. Neither the forms nor the Receptacle are concrete, so where does the concretion of actual things come from?

Of course the Timaeus does not contain Plato's only reflections on individuation. More commonly associated with Plato's name is the idea that the individual was an imperfect copy of an ideal original, an image participating in (but never coinciding with) the form. This idea never sat well with Aristotle. Aristotle understood the theory of participation to mean that concrete individuals were less actual than the universals (forms) they exemplified. He did not see how the forms could lack concreteness and yet be actual or how concreteness could be explained as the attenuation of an actuality that was not itself concrete. He thought Plato was engaged in the impossible task of deriving the concrete from something not concrete, but supposedly more primitive. Ironically, this is also how Aristotle was understood by seventeenth century philosophers, who thought Aristotle's essence or substantial form was an abstraction, a hypostatized ens rationis, that was somehow supposed to cause its possessor to be a concrete instance of itself. Whitehead believes that Aristotle's seventeenth century critics rediscovered Aristotle's own doctrine of the intrinsic concreteness of actuality in their insistence on grounding philosophy in the concrete experience of subjectivity. ${ }^{36}$

\subsection{Intuitionistic Theories of Individuation}

Aristotle thought there had to be more to a thing's individuality than its numerical distinctness or even its difference from all other things. Relative position, for example, is enough to discriminate otherwise identical things. But how could the concreteness of something depend on relative and accidental properties? Moreover, essential properties and intrinsic differences, in and of themselves, don't help us out of this problem either. A particular shade of red is essentially different from all other colors, but that does not make it an individual thing. And, finally, two patches of the same color aren't different because you can count them; you can count them because they are different. Aristotle's conclusion was that concreteness is something primitive and inexplicable. Duns Scotus, however much he may diverge from Aristotle's theory of individuation (and this continues to be a subject of debate), agrees with Aristotle on the one cardinal point, which is stressed by Whitehead as well: individuality 
must be primitive. It cannot come from any prior principle. It cannot be constituted. Nothing that is not already individual could give rise to individuality. For Scotus this means that haecceitas is a "formal" part of every individual thing. ${ }^{37}$ For Aristotle it means that a this cannot come into being absolutely; it cannot be generated from antecedents that are not already in possession of thisness. The application of this principle to biology results in Aristotle's doctrine of the eternity of the species realized in the cyclical becoming of its individuals: a this comes only from a this of like type - a horse produces a horse; a man produces a man.

To some, the insistence on concreteness may seem question begging. Perhaps nothing really is concrete in this sense Aristotle was so fond of. So let's return to the Receptacle and ask how it makes even numerical distinction possible, regardless of the question of concreteness. The only feature that seems to belong intrinsically to the Receptacle is its expanse as a spatial matrix. Accordingly, we could try to explain numerical individuation as a function of differential location in this matrix. This is indeed a very common recourse taken in the history of philosophy, but the result is to burden space with the whole mystery we were trying to explain in the first place: if contentless space is itself without qualities, undifferentiated, and everywhere the same, what makes two places different?

One reaction to this challenge is to concede the argument and, like Leibniz, base the differentiation of space on the differentiation of its content. On this account it would be impossible for there to be any two completely identical things. Similarly, exactly one and the same quality could never be extended in space. Extension in space would only be possible as a function of continuous qualitative difference. Another reaction to this challenge is defiance. Kant makes the strongest showing here. He believes that purely numerical individuation is a brute fact that can be easily documented and that this brute fact has unique metaphysical importance. For it proves that space, precisely because we cannot specify the nature of its peculiar contribution to experience conceptually, is something metaphysically primitive, something that cannot be derived from its content or from any specifications employing universals. This is the context in which Kant's paradox of incongruent counterparts must be evaluated: it documents the alleged brute fact by generating a mathematically irrefutable counterexample to Leibniz' Principle of the Identity of Indiscernibles. Simply by reversing the plus and minus signs, the equation for a clockwise conical spiral becomes the equation for a counterclockwise conical spiral that is necessarily identical in all respects to the clockwise spiral - except for the stubborn fact that the two spirals are 
distinct numerically. They are distinct for the obvious reason that they cannot be brought to coincide - no more than you can put your left hand into a right-hand glove, even though the two gloves are morphologically identical.

It is a very curious fact that Kant deployed the paradox of incongruent counterparts twice in his career: in the pre-critical period to prove the reality of space and then in the critical period to prove its ideality! Perhaps this means it proves neither. What it does prove is that the Leibnizian theory of space is wrong: space is not the order of coexisting differentials. It must be a principium individuationis sui generis. The metaphysical reality and the transcendental ideality of space are both attempts to make sense of its stubborn autonomy vis-à-vis thought and its machinery of concepts and universals.

The aim of Kant's argument from incongruent counterparts is the same as the aim of his arguments about time and space in the "Transcendental Aesthetic:" to prove that "to be" means to be unique in ways that defy conceptual specification. A recent contribution to this very old debate has been made by Michael Dummett. ${ }^{38}$ The lesson Dummett draws from McTaggart's refutation of time strikingly recalls Kant's thesis. Dummett shows that to be in time means to be individuated in ways that defy purely conceptual specification. Reflections of this sort inevitably bring us back into the proximity of something like the ineffable concreteness invoked by Aristotle or Scotus.

\subsection{Logicist Theories of Individuation}

The other doctrine, which identifies individuality with specificity, is very satisfying to the logically minded because it eliminates - at least in principle - anything from the world that cannot be completely specified by concepts, that is, anything that cannot be picked out uniquely by definition or description alone. It envisions a world just like that of Stoics physics or Leibniz' monadology or Aristotle's supra-lunar world of stellar intellects where the Principle of the Identity of Indiscernibles holds absolutely. Nothing can then be numerically distinct without being specifically distinct. In principle, science should be able to proceed unencumbered by the problem posed by individuals that are distinguished only indexically. The fact that logicians have often had such an ideal of individualityreduced-to-specificity in mind, however vaguely, explains perhaps a fallacy identified for the first time by Frege. It is not uncommon in the history of logic to find conflated two very different logical relations: the subsumption 
of an object under a concept (the inclusion of a thing within the extension of a class) and the subordination of one class-concept (e.g., a species) to a higher class-concept (e.g., a genus). Predicating a concept of an individual thing is very different from predicating a concept of a concept - unless, of course, the individual is simply a most specific species. In that case it coincides with the species, which becomes a class that has only a single member, making the difference between the class and its unique member easy to overlook and hard to pin down. What makes the token different from the type it uniquely satisfies? This appears to be the same question posed above: what makes the instance different from the form if the Receptacle contributes nothing to what the instance is?

An important point needs to be highlighted. In the possible world we are envisioning, where individuality reduces to greatest actual specificity, there would be no logical, only a pragmatic need for proper names or for demonstrative expressions such as this, that, here, there, now, then, I, you, etc. What these words have in common is the ability to designate things immediately, without identifying them by descriptive specification. It is a way of designating things that is conceptually ("intensionally") unmediated. The unique importance of this kind of reference has been emphasised numerous times in the history of philosophy. In his Logic, Mill recognizes it as the function of proper names. In the first Critique, Kant recognizes it as the function of intuition. In our own century this peculiar function has captured the attention of both Continental and AngloAmerican philosophers. Russell assigned this function to "logically proper names." Husserl called it reference by "essentially occasional expressions," meaning all terms whose meaning depends on the context of utterance. Analytic philosophers have called it "indexical" or "token-reflexive" reference and developed a causal theory of meaning to account for it. From Kant's intuition to Russell's logically proper naming, all these functions are forms of token-reflexive cognition that presuppose the involvement and participation of the subject in the world it knows. In the logicist world we are imagining, where everything could be identified by its unique description, immediate reference of this sort would be metaphysically superfluous, however convenient it might be. If this function is metaphysically superfluous, then "knowledge by acquaintance" (by which I mean acquaintance with particulars) is necessarily a deficient mode of knowing something that could be more properly known by description alone.

The crucial questions thus become: is knowledge by acquaintance and token-reflexive participation in the world something that science should properly aim at replacing with a wholly objective knowledge by 
description? Is the only scientific function of acquaintance to provide us with explananda, but never with explanantia? ${ }^{39}$ There are three possibilities here.

(1) Positive answer. However difficult, it is in principle possible to replace knowledge by acquaintance with knowledge by description that relies on no acquaintance at all. The proper activity of science is to explain the content of acquaintance without relying on acquaintance. (This is the concept of science that Carnap expressly sought to justify in Der logische Aufbau der Welt, $\S \S 13-17$.) Acquaintance is therefore a kind of true belief that science replaces with knowledge.

(2) Qualified negative answer. It is impossible to replace knowledge by acquaintance entirely with knowledge by purely objective description, but this impossibility stems only from our own cognitive limitations.

(3) Unqualified negative answer. It is impossible to replace knowledge by acquaintance entirely with knowledge by purely objective description, and this reflects something fundamental about the nature of the things we seek to know.

(1) The idea that intuition is a deficient way of being apprised of something that concepts alone can actually know should remind us of Leibniz's idea of perception as nothing more than confused intellection. But what does it mean to say that science, under ideal circumstances, could dispense with acquaintance? The idea of a wholly "objective" cognitive methodology has played a powerful role in the history of philosophy and science. But the requirements of such a method are not often followed to their logical extreme, which is: it is possible to explain (or at least to specify) any fact of acquaintance without presupposing any facts of acquaintance. In other words, whatever we know by acquaintance we could also (and more properly) know in a way that doesn't depend on any acquaintance with anything - including ourselves. Stated in this way, such an idea may seem absurd. But it has lurked in more than one gifted mind. It is behind Leibniz's idea that everything that can be known a posteriori can also be known a priori, i.e., every fact can ultimately be deduced from truths of reason. And this is just what we would expect a committed logicist to say. Nevertheless, Leibniz admits - almost grudgingly - that much of what we know we will only know a posteriori. To God is reserved the ability to know everything a priori. In the end his position appears to be alternative two.

Leibniz's commitment to this extreme idea of science is patent, and his articulation of it is paradigmatic in its clarity and simplicity. But he is not 
alone. A little scrutiny finds the same idea behind a range of scientific programs that seem on the surface to have little in common.

Echoes of Leibniz's idea resound among the German Idealists, who have long been ridiculed for allegedly thinking that from reason they could deduce everything a priori-facts of experience, laws of nature, and even their own place in the history of philosophy. While such criticism is often poorly informed on particulars and cannot be taken at face value, it is not without justification. It is true that Fichte, Schelling, and Hegel all demanded that science proper make no presuppositions, least of all the presupposition of positive empirical data. Science proper could therefore be nothing other than a speculative philosophy that proceeded through a chain of necessary deductions from an absolute first principle to the derivation of particular truths. Just how far this deduction could go was the question that generated controversy from the start. Already in 1801 Wilhelm Krug mocked the project of deduction, which Schelling, in his System of Transcendental Idealism, had proclaimed with characteristically inelegant bravado:

Speaking as a physicist, Descartes said: give me matter and motion and I will build the universe out of it for you. The transcendental philosopher says: give me a Nature of opposite activities, of which one proceeds infinitely and the other endeavors to intuit itself in this infinity, and out of that I will make Intelligence along with the entire system of its representations emerge for you. ${ }^{40}$

To understand the scope of this claim it is only necessary to know that "system of representations" means the empirical world. And, to be sure, the Idealists claimed to deduce natural phenomena (such as matter, magnetism, organic life), as well as general laws of nature and the general course of world history. However, on the grounds that contingency is one of the things that is absolutely necessary, they were able to avoid the full burden of deducing particular facts. Krug took them to task for this. He accused them of false promises and defied them to deduce even one empirical phenomenon, famously proposing his quill pen. ${ }^{41}$ In response, Schelling and Hegel insisted that it is only the system of phenomena that is rational and thus deducible. ${ }^{42}$ However, because the line between system and positive fact was fluid, the limit case of exhaustive a priori deduction always hovered over their program of Naturphilosophie, whether as an impossible ideal or as a reductio ad absurdum.

Laplace's determinism proved to be a less laughable project of deducing particulars. Its great summary statement deserves to be quoted:

All events, even those which on account of their insignificance do not seem to follow the great laws of nature, are a result of it just as necessarily as the revolutions of the sun. [...] We ought then to regard the present state of the 
universe as the effect of its anterior state and as the cause of the one which is to follow. Given for one instant an intelligence which could comprehend all the forces by which nature is animated and the respective situation of the beings who compose it - an intelligence sufficiently vast to submit these data to analysis - it would embrace in the same formula the movements of the greatest bodies of the universe and those of the lightest atom; for it, nothing would be uncertain and the future, as the past, would be present to its eyes. ${ }^{43}$

Although Laplace is rightly held in much greater scientific esteem than the likes of Schelling, they share a concept of science defined by the impossible limit case of exhaustive deduction, as comparison of Laplace's summary statement with the following passage from the System of Transcendental Idealism shows:

Thus, for example, sensation is an act of the ego, which, were it possible to demonstrate all of its middle terms, would lead us to a deduction of all qualities in nature, which is impossible. ${ }^{44}$

Laplace proposed what we now call a "covering-law" or "nomologicaldeductive" model of scientific explanation: particular events are explained by deducing them from antecedent events by means of general laws. Such a model is implicit in Newton's Principia, albeit not in the universalized form that implies strict determinism. Explaining natural events by general laws is in effect a way of deducing what is known by acquaintance from what is known by description or, to put it differently, a way of reducing acquaintance to description. Of course, while acquaintance is eliminated in the covering laws, it crops up again in the specification of the boundary conditions. In this context, we can see why Laplace's revision of Newton's cosmology had unusual significance for philosophy. Because Newton's deistic universe needs occasional rewinding by God, even Laplace's imaginary intellect would be unable to deduce its history and future from its present state. Periodic acquaintance with new and undeducible boundary conditions would always be required. But Laplace (and, ironically, Kant in his great pre-critical work on the "natural history" of the heavens) showed how the boundary conditions themselves (all but the very first) could be generated by the covering laws, thus bringing us one tantalizing step away from a purely objective methodology. Needless to say, revisions in cosmology do not usually have epistemological ramifications. In this case, however, a concept of science that had previously been the fantasy of speculative idealism was given universal legitimacy. What the example of Laplace demonstrates is that the ideal of science disengaged from any constitutive reliance on acquaintance is a more familiar figure than my initial characterization may have led the reader to believe. It is well known and often trusted under names such as determinism, materialism, or just plain science. 
This idea continues to play an important role in contemporary discussions of science. It seems entirely reasonable to suppose that the perspectivity and subjectivity that characterize the empirical act of knowing are contingencies of the act irrelevant to the nature of what is knownpresumably even in the case where it is ourselves we are seeking to know. This leads to an ideal of knowledge that would wholly eliminate from its content any residues of its contingent genesis. This is the implication of the common idea that knowledge is objective (i.e., is knowledge in the strictest sense) to the extent that it has eliminated or overcome subjectivity. The problem with such an ideal is that no cognizance could be taken of the act of cognition itself as a real psychological or psychophysical event happening at some place and time, unless, of course, this fact were itself arrived at in a purely objective way, rather than subjectively by selfacquaintance. But self-cognizance by acquaintance is implicit in all indexical language (as that in reference to which something is here or there, now or then, etc.), making the elimination of this vestige of subjectivity depend on the elimination of all indexical terms from scientific description. This brings us right back to the logicist theme of explaining or describing facts of acquaintance in a way that presupposes no facts of acquaintance, for being objective (in this sense) simply means relying at no point on an indexical anchor to execute a description of the world or the self it contains. At one point in his Logical Investigations, Husserl, of all people, imagines the possibility of such a scenario, invoking an "ideal" equivalence between the actual momentary denotation of essentially occasional expressions and corresponding absolute space-time coordinates! $!^{45}$ And even (or especially) in his phenomenology, which germinates from ideas in his Logical Investigations, Husserl shows a keen interest in freeing consciousness from its psychological reality: transcendental consciousness is prior to and independent of its tokening as this consciousness. Phenomenology thus appears to be a science that does not in fact presuppose the act of cognition as a real psychological or psychophysical event happening at some place and time.

Because a purely objective description cannot take advantage of its own perspective, Thomas Nagel has dubbed it "the view from nowhere." ${ }^{46}$ It would have to enter the world not only "from nowhere" but also from "nowhen," excluding not only indexical time words, but also any use of tense (tense is essentially token-reflexive, establishing temporal position relative to the time of enunciation). These constraints seem impossible to meet and call into question either the possibility of objective knowledge or the way we have been construing objectivity. However unreasonable this interpretation of objectivity may seem once it is cast as an ideal of description that relies on no acquaintance, not a few philosophers have 
invested in it in the name of reason. Husserl is perhaps the most explicit, insisting in the Logical Investigations that the possibility of replacing "subjective" with wholly "objective" expressions, while "factically" impossible, is ideally and in principle demanded by the "unlimitedness of objective reason" (Schrankenlosigkeit der objektiven Vernunft). ${ }^{47}$ Here again, just as with Leibniz, Schelling, and Laplace, science is defined by an idealized limit case whose impossibility is not denied. This makes all four concepts of science edge away from alternative one, which they proclaim, towards alternative two, which they concede.

Because the major transitions in his philosophical thinking present an object lesson in the problem of "objective description," Husserl's example deserves close examination. Making the rationality of the world depend on absolute space and time is obviously something Husserl gave up with his discovery of phenomenology, but it is in precisely this context that we can appreciate the genius of his concept of phenomenology, for it turns out to be another way to satisfy the same demands of "unlimited objective reason." It is actually a better way, since objectivity is now an ideal that is supposed to be realizable rather than counter-factual in its normativity. The trick is that the "phenomenological reduction" necessarily includes what Husserl calls the "eidetic reduction": the reduction of all individuals to their corresponding types. Phenomenological description thus turns out to be nothing less than the realization of the logicist concept of science: an exhaustive description of the world that employs universals alone, never relying on the token-reflexive indication of individuals. Just how extraordinarily peculiar the resulting description is (the world as the content of absolute consciousness) is probably a good measure of how overextended the original demand for a "token-free" objectivity was. These last reflections also point up a connection as unexpected as the one suggested above between Schelling and Laplace. For Husserl's phenomenological reduction appears to have something in common with the ether that contemporary physicists were seeking: transcendental phenomenology and absolute location are both ways of eliminating tokenreflexivity from our description of the world. A further comparison is also possible, for it is questionable whether absolute consciousness is any less quixotic than the ether. Indeed, Husserl himself eventually came to recognize not one but two fatal threats to his logicist interpretation of phenomenology as a rigorous science: first, the temporality of consciousness, which binds it to the critical index of the now, and, secondly, the dependence of consciousness on the life-world, which binds it - and every essence it discloses - to the factical givenness of its particular historical milieu. It is bound, in other words, to the world that can be identified only demonstratively as this one. 
The twentieth-century fascination with the ideal of purely objective knowledge was of course not limited to Husserl. It was characteristic not only of the Vienna circle and the early Wittgenstein, but also of much analytic philosophy of science. Positivism and its analytic legacy were actually more dogged proponents of the "unlimitedness of objective reason" than phenomenology, since Husserl at long last gave up on it. Doggedness notwithstanding, positivism and analytic philosophy both offer case studies of the failure of "objective reason" as trenchant as the example of phenomenology. Positivism runs almost parallel to phenomenology, since in both cases attempts to realize the dream of purely objective knowledge led conspicuously in the very opposite direction. Husserl was led to the life-word as the ultimate foundation of all knowledge. Because the life-world, being the presupposition of all objectifying knowledge, is itself unobjectifiable, reason cannot take possession of it and must simply acquiesce to its ultimacy, despite its lack of rationally desirable features such as transparency or exact delineation (i.e., clarity and distinctness). It was Husserl's realization that meaning and essence depend on the lifeworld, and not the other way around, that led him to his famous confession that "the dream of philosophy as a rigorous science is dreamed out $[\ldots]$ "48

In its search for objectivity the Vienna Circle also found itself mired in subjectivity. For it was led to a doctrine according to which the most basic scientific truths would all be of the sort "Here now red," in other words: token-reflexive reports of subjectively experienced sense data. ${ }^{49}$ Far from eliminating acquaintance from science, this program ends up basing everything on it. It was Karl Popper who recognized that this theory of science contributed nothing to the objectivist program it cherished and was in fact an extreme form of psychologism. Just as the nineteenth century attempt to derive the laws of logic from the way human beings think compromised the universal validity of logic, so, Popper argued, the attempt to derive empirical statements of science from private perceptual experiences compromises their objectivity. ${ }^{50}$ Since the gap between actual cognitive experience and objective reason proved to be unbridgeable, we should not be surprised at Popper's astoundingly radical proposal for salvaging the latter: to treat "protocol sentences" not as records of psychological events, but as intersubjective conventions. ${ }^{51}$ Unfortunately, this leaves unanswered whether there might be better and worse conventions of this sort and by what criteria - other than the psychological ones we wanted to avoid - we might evaluate them.

As a final case study of the failure of objective reason I mention the debates about meaning in analytic philosophy. What Putnam's argument in "The Meaning of 'Meaning" ${ }^{52}$ comes down to is this: that there is a latent 
indexical component in all referring terms. The causal theory of meaning implies that it is not only impossible to pick out an individual by specification alone, but that it is even impossible to refer to a type by specification alone. All type names are token-reflexive in that they presuppose the types of things found in this world, with the latent properties they have here rather than in some other possible word where things look the same, but would have different latent properties. For when, in the fullness of time, we uncovered the latent differences, we would rightly insist that it was our types we had been referring to all along, even though, ex hypothesi, it was impossible for us to specify our types so as to discriminate them from their Doppelgänger. But that means that all along we were referencing them indexically.

The upshot of this argument is that all terms are essentially occasional expressions in Husserl's sense: they refer to things of various descriptions only insofar as such things are the ones found in this world. Remarkably, this is the same conclusion Husserl had finally come to. Because they are rooted in it, even essences presuppose the life-word, which cannot in turn be reduced to an essence. Instead, it is an ultimate fact. In his Logical Investigations Husserl had proposed a taxonomy of intentional acts according to which only objectifying acts (acts that specify an object) can be thetic or non-thetic (affirming or denying the existence of something). This amounts to saying that we do not affirm the existence of anything we cannot objectively describe. In conceding in the Krisis that the life-world is necessarily given in the manner of a non-objectifying thesis, Husserl has in fact conceded that the life-world is given causally and can be signified only indexically. The rootedness of essences in the life-world thus means that they cannot be purged of their intrinsic reference to something that can be identified only token-reflexively, which is the very conclusion Putnam has made famous.

(2) A qualified negative answer is given by those who do identify individuality with specificity, but concede that the limitations of our faculties and the complexity of the world render it such that we will always have to rely on acquaintance in our scientific explanations. Because our concepts never reach the requisite specificity, we fall back on intuition, which gives us the power to discriminate things without actually understanding their differences. Here we find, with varying degrees of chagrin, most of the figures discussed already under alternative one: Leibniz, Schelling, Laplace, and the Husserl of the Logical Investigations. For all of them, the logicist ideal is indispensable as the norm for a real knowledge that mostly falls short of it. It is the knowledge that an infinite intellect actually has (Leibniz), or the knowledge that an infinite intellect 
would have if there were such a thing as an infinite intellect (Laplace), or the knowledge that we would have if contingency weren't necessary (Schelling), or the knowledge that we would have if the demands of reason were "factically" fulfilled. Our knowledge is knowledge in the truest sense only to the extent that it measures up to this ideal, which it can sometimes do qualitatively (some of what we know can be specified by description alone and is certain a priori), but not quantitatively (most things we cannot know a priori by description alone). The rest of what we know is not knowledge stricto sensu, but a true belief in the modern sense, for the facts we are thus acquainted with have a rational etiology, even if we cannot know it.

We should note that Schelling's counterfactual conditional "if contingency weren't necessary" is tantamount to "if individuality were specificity," which is therefore a concession that individuality is in fact not specificity. This pushes Schelling's metaphysics down under alternative three, while keeping his concept of science attached to alternative one: knowledge stricto sensu is specification. This implies that individuals are indeed more than specificity, but by the same token cannot strictly speaking be known, even though we can be acquainted with them-a position he seems to share with Plato in the Timaeus. For Schelling, acquaintance with individuals would therefore seem to be a form of true belief more in the tradition of Plato and Aristotle-something that lacks a rational etiology because it is true only "by accident." As for Husserl's counterfactual conditional, "if the demands of reason were factically fulfilled," it is impossible to imagine what a world in which they were fulfilled would have to look like. Husserl seems to be thinking of absolute space-time coordinates as last differentiae, and thus as the ultimate part of each thing's specificity. How could these differentiae be known? Perhaps they would be known to God if, as Newton speculated, absolute space were His sensorium, but we would have to add absolute time as a sensorium as well.

A qualified negative answer seems to come from the Stoics too, for they also believe that description cannot replace acquaintance even though individuality is simply unique specificity. But their rationale is unlike that of Leibniz or the others just discussed. For Leibniz, acquaintance is confused description, and it would be better to do without it if only we could. God does know conceptually what we can only know by intuition. Similarly for Laplace or Husserl in the Logical Investigations, we fall back on acquaintance because the adequate description, while not a metaphysical impossibility, is not available to us. For the Stoics, however, intuition is not inferior to thought. On the contrary, their katalepsis is sensuous, not 
conceptual, and yet they decidedly believe in the identity of indiscernibles and hence the logical character of all individuality. This puts them in the curious position of identifying individuality with unique specificity while believing that intuition is the eminent mode of cognition. This combination of theses is possible only if intuition is a way of specifying (rather than demonstratively indicating) an object. How can intuition be a mode of specification?

The crux is their belief that sensuous intuition is not less, but more clear than thought. This seems to have been suggested to them by the fact that the finest qualitative discriminations are ineffable. From this they made a remarkable inference. If what defines thought is the fact that it operates exclusively with general concepts or universals, this is because thought is simply specification that has stopped short of picking out an individual uniquely. Description by concepts is incomplete specification because complete specification is always ineffable intuition. Thus, while they agree that it is impossible to replace acquaintance with description (even though individuality is just unique specificity), this implies something about the limitations of thought rather than about the limitations of our ability to have thoughts. Only acquaintance succeeds in going all the way to the point of capturing an individual in its unmistakable uniqueness. Their katalepsis is therefore a kind of acquaintance. It is the highly nuanced acquaintance of the skilled artisan or connoisseur, able to discriminate so finely that even the most similar individuals are not confused. This is confirmed by an amusing passage in Cicero's Academica. In discussing Stoic doctrine, Cicero illustrates the sort of wisdom that is supposed to define the Stoic sage with the satirical example of a poultry keeper allegedly so practiced at his trade that he could discriminate one egg from another: simply by looking he could determine which hen had laid it! $!^{53}$

But even if katalepsis is a kind of acquaintance, it differs from all the other kinds of acquaintance discussed in a fundamental respect. They all assumed an essential indexical component. The Stoics' katalepsis, however, is not token reflexive. Even though its grasp of extreme nuance presupposes the ineffability of tacit knowledge and the embodied skills of discriminative competence that we normally associate with the tokenreflexivity of the first-person, performative attitude, it actually targets something that is not context dependent and could in principle be picked out of a cosmic line-up. The individual is discriminated by its qualitative peculiarities alone. For the Stoics, katalepsis is simply discrimination that has reached the most extreme possible degree of nuance and therefore reveals the unique specificity of its object. Thus, their position has in common with intuitionists the reliance on acquaintance at the same time 
that they remain committed logicists who deny that individuality is anything more than specificity. This position is not impossible to fathom if we bear in mind that all the qualia of perception can be construed as universals. This allows the object of intuition (an individual) to be construed in a logicist fashion as a unique combination of universals. Since this is Whitehead's way of understanding qualia, his infinite abstractive hierarchy may be a modern equivalent to the Stoics' "kataleptic presentation" (the sensuous content of the act of katalepsis). Whether Whitehead is thus committed to the same theory of individuality as the Stoics will be discussed in part four or this paper.

(3) The wholly negative answer to this question is given by the intuitionistic theories of individuation we considered first. If individuation is more than specificity and identical individuals are possible, tokenreflexive acquaintance will be our only way to keep track of them. We saw that this was the answer of Aristotle, Scotus, and Kant.

The following table summarizes the results of this section:

Table VII

\begin{tabular}{|c|c|c|}
\hline & $\begin{array}{c}\text { Individividuality Is More } \\
\text { Than Specificity }\end{array}$ & $\begin{array}{c}\text { Individiduality Is } \\
\text { Extreme Specificity }\end{array}$ \\
\hline $\begin{array}{c}\text { Individividuality } \\
\text { Is Only Knowable } \\
\text { By Intuition }\end{array}$ & Aristotle & Stoics \\
\hline $\begin{array}{c}\text { Individividuality } \\
\text { Is Only Knowable } \\
\text { By Concepts }\end{array}$ & Kant & Plato's Timaeus (?), \\
Schelling ca. 1800 & Leibniz \\
\hline
\end{tabular}

Husserl is omitted from the table because his placement is complicated by conflicting commitments. His concept of reason requires him to take his position as a metaphysical and epistemological logicist alongside Leibniz, while his theory of evidence makes him, at the very least, an epistemological intuitionist like the moderns (other than Leibniz) discussed in the previous section. We have seen how the impossibility of reconciling these two commitments compelled him at last to abandon one of them. 


\section{Whitehead's Theory of Individuation}

We have seen that numerous senses of abstractness are to be found in SMW. They differ from one another in philosophically important ways that Professor Wiehl has delineated. We have also seen how privileging one of the senses of abstractness over the others can bring us into alignment with very different factions in the traditional debate about individuation. We have reviewed that debate and discussed complications and peculiarities famously associated with the major factions. It remains now for us to determine Whitehead's own allegiance in this debate. Because Whitehead shares motives and concerns with both of the major factions we have discussed, determining his own position is not as straightforward as it might seem at first. Let's begin with a schematic recapitulation of our argument so far.

We sketched the history of the debate about individuation from two analytic perspectives: epistemologically in part two and metaphysically in part three. Epistemologically it appears as a dispute over the relative value of intuition and intellection for securing knowledge of individuals. Metaphysically it appears as a dispute over whether the principium individuationis is some kind of conceptually unspecifiable singularity or just a unique extreme of specificity. The following matrix combines the analytic perspectives of the previous two parts:

Table VIII

\begin{tabular}{|c|c|c|}
\hline $\begin{array}{c}\text { Theories of Cognition vs. } \\
\text { Theories of Individuation }\end{array}$ & $\begin{array}{c}\text { Intellection Eminent } \\
\text { \& Intuition Deficient }\end{array}$ & $\begin{array}{c}\text { Intellection Deficient } \\
\text { \& Intuition Eminent }\end{array}$ \\
\hline $\begin{array}{c}\text { Intuitionistic } \\
\text { (Individuality Is }\end{array}$ & $\begin{array}{c}\text { Plato, Thomas Aquinas, } \\
\text { Schelling ca. 1800 }\end{array}$ \\
$\begin{array}{c}\text { Singularity Beyond } \\
\text { Specificity) }\end{array}$ & $\begin{array}{c}\text { substances), Duns Scotus, } \\
\text { Nominalists, Locke, Kant, } \\
\text { Neo-Kantians, [Husserl] }\end{array}$ \\
\hline $\begin{array}{c}\text { Logicist (Individuality Is } \\
\text { Specificity) }\end{array}$ & $\begin{array}{c}\text { Parmenides, Aristotle } \\
\text { (re: separate substances), } \\
\text { Spinoza, Leibniz, } \\
\text { [Husserl], Positivism, } \\
\text { Determinism }\end{array}$ & Stoics \\
& \multicolumn{2}{|c}{} \\
\hline
\end{tabular}

Back in part one we proposed an interpretation of the two types of transcendence/abstractness alluded to by Professor Wiehl in PU. Let's 
recall the relevant two types and use our analytic matrix to sharpen the contrast between them. In sense one of transcendence (hereafter: $\mathrm{T}_{1}$ ) all that universals necessarily lack is haecceitas, not adequate specificity, and this lack is enough to secure their potential for multiple instantiation. In sense two of transcendence (hereafter: $T_{2}$ ), to be universal means to fall short of complete specificity and thereby be able to apply to a number of things that are partly or generically, but not completely or specifically identical in type. Haecceitas as something distinct from extreme specificity is crucial to the theory of individuation implied by the former construal of universals and superfluous to the one implied by the latter.

Giving precedence to $T_{1}$ leads to what $I$ have called intuitionistic theories of individuation, such as we find in Aristotle, Scotus, or Kant, and typically to the promotion of some kind of token-reflexive acquaintance as an eminent mode of cognition giving us privileged access to individuals. This token-reflexivity may, but need not be, recruited metaphysically to explain the very nature of individuality. This metaphysical strategy was used by Kant, but not, for example, by Aristotle. What Kant and Aristotle have in common is the epistemological idea that token-reflexive acquaintance is indispensable if we are to be cognizant of individuals that possess individuality beyond specificity.

Despite its partial anticipation by Aristotle (in the case of composite substances) and Scholastics such as Scotus (in one sense) and the Nominalists (in another sense), this epistemological idea tends to be more prominently associated with modern rather than ancient positions. For as soon as we add that there are no other individuals than the ones that have to be accessed by means of token-reflexive acquaintance, we arrive at a thesis that is recognizably modern even if its roots are in Scholastic Nominalism: that there are no "intelligible" individuals; the only individuals are the sensible ones, and everything non-sensible is an "abstraction." Sensuous intuitability thus becomes a test of reality, and sense perception becomes an eminent mode of cognition. Of course it is possible, like Plato, Aquinas, or Schelling, to combine an intuitionistic theory of individuality with an insistence on intellection as the eminent mode of cognition. What this implies is that individuality, insofar as it evinces singularity beyond specificity, is something accidental and metaphysically tawdry. It is, to be sure, knowable by token-reflexive acquaintance, but this is "knowledge" in a very weak sense and hardly worth having.

Giving precedence to $T_{2}$ leads to what I have called logicist theories of individuation and, exceptions such as the Stoics notwithstanding, usually leads to the denigration of acquaintance as a deficient mode of approach to individuals. ${ }^{54}$ This position is usually thought of as ancient because it sees 
true individuality as something revealed to thought rather than intuition. The Greek word for something revealed to thought is noumenon. The fate of this word in modern philosophy is a good measure of how far from ancient ideas modern thinkers wanted to be. Nevertheless, logicians such as Leibniz and many of the nineteenth century Platonizing philosophers of logic were happy to rehabilitate intellection as an eminent mode of cognition. Furthermore, logicist ideas seem to have played an unadmitted or at least an underestimated role in modern conceptions of scientific knowledge that posit an ideal of wholly objective (standpoint-independent) or nomologically exhaustive (deterministic) content. Implicitly at least, these conceptions identify individuality with specificity and make intellection the eminent mode of cognition, but they remain essentially modern in that they deny the existence of separate individuals that are intelligible without also being (in principle) sensible. In other words, they posit individuals that are wholly intelligible without being only intelligible. This means that we can know by objective description every individual we are acquainted with, but also, at least in principle, that we can be acquainted with every individual we know by description. By contrast, the Platonizing logicians of the nineteenth century are rehabilitating a characteristically ancient idea when they posit, among others, individuals that are intelligible only, intrinsically incapable of becoming the object of intuitive acquaintance.

Although logicist theories of individuation typically promote intellection as an eminent mode of cognition giving us privileged access to individuals, it is possible, as the example of the Stoics proves, to combine a logicist theory of individuation with an insistence on intuition as an eminent mode of cognition. What this means is that the qualitative nuance of intuition achieves a specificity that not only surpasses thought, but also suffices to pick out an individual by its absolute properties alone, without any reliance on relational properties connecting it with the act of intuition as something happening at a given place and time.

How to go about situating Whitehead in our analytic schema? Let's begin with the simplest question: does he subscribe to the ancient or the modern view of cognitive modes? The ancient view allows thought and intuition to have separate objects and inevitably grants eminence to thought, while the modern view makes thought a deficient way of knowing the same thing that intuition knows eminently. There can be no doubt that Whitehead is in one sense wholly modern: thought and intuition are two ways of knowing the same individuals. But the situation is not as straightforward as it first seems because thought and intuition, while knowing the same individuals, do have separate objects (eternal objects versus actual occasions). 
Everything therefore hinges on how these separate objects are related to one another so as to converge in the same individual. We will find that this complication puts all the options, ancient and modern, back on the table, and makes all our other questions extremely difficult to answer: which mode of cognition is eminent and which is deficient and why? Is individuality unique specificity or singularity beyond specificity? If we follow Whitehead's arguments one by one, we will find him migrating from one position to another or even insisting on combining elements from contrasting positions. Therefore, assuming Whitehead's position is not always vacillating (or simply incoherent), we will be able to discover its unity only if we can also expose critical limitations in our analytic schema as it now stands. So let's pause here to say something about the genesis of this matrix and its adequacy.

With the topic of the matrix being individuation, its two parameters are epistemological position vis-à-vis individuation and metaphysical position vis-à-vis individuation. These are the variables of our analysis. As an inductive survey of well-known historical positions, the preceding two sections strongly suggest that only two values are possible for each variable and, in fact, the same two in each case: metaphysically one is either a logicist or an intuitionist, and epistemologically one is either a logicist or an intuitionist. Despite a tendency for the metaphysical and epistemological perspectives to run parallel, it's obvious from our historical survey that the two parameters represent independent variables: one's metaphysical position on individuation tends to influence, but does not constrain, one's epistemological position on individuation, and vice versa. This yields our matrix of four possibilities. If adequacy in the representation of possible positions is wanted, a simpler matrix than this is not possible. But, based on our historical survey, a more complex matrix does not seem possible either, which suggests that it is a complete taxonomy of possible theories of individuation. As an inductive conclusion based on limited samples, this conclusion is tentative. If we look at the matrix as an inductive hypothesis, then what I am doing in this section is testing the adequacy of the hypothesis against a new slate of data, which confronts us in the form of Whitehead's remarks on individuation in a variety of contexts over a period of roughly twenty years.

The argument will proceed dialectically. Mindful of their chronology, I will examine several important texts concerning individuation in Whitehead, considering different possible interpretations of each, especially in light of the others and their possible interpretations. In the first section I address the epistemological question (which mode of access to individuals is eminent?) and in the second section the metaphysical one (is 
individuality unique specificity or singularity beyond specificity?). In each section I begin with SMW, considering the implications of the theory of individuation I extracted from the chapter on abstraction in the first part of this paper. This gives us preliminary answers to our two questions. I proceed in each section by comparing these results with Whitehead's pronouncements about individuation in other works, revisiting earlier conclusions as necessary. The third section suggests how our analytic schema needs to be revised if we are to find coherence in the many views Whitehead seems to express. It will be useful to keep the chronology of the relevant works in mind as we proceed: PNK, CN, SMW, S, PR, AI.

\subsection{What is the Eminent Mode of Access to Individuals for Whitehead?}

4.1.1. Let us begin our discussion of this question by noting Whitehead's obvious deep sympathies with the intuition faction, which is evident in his understanding of mentality as discussed in part one above. According to the passages cited from SMW, thought will never grasp an individual because thought operates with a finite number of universal qualifications, while the individual involves an infinite complexity. Whitehead's understanding of mentality in SMW therefore implies that intellection cannot possibly be an eminent mode of cognition. This much seems certain. But how does he stand in regard to intuition? This is more difficult. For example, if, like Kant, we understand intuition as a mental function of a peculiar sort (characterized namely by immediacy), then we encounter the obvious problem: for Whitehead, nothing "mental" reaches all the way to individuality. How then do we ever become cognizant of individuals according to Whitehead? If we do have truck with individuals, it would have to be by way of an experience that was not mental! And this is indeed Whitehead's teaching, which can be documented in all of the works that concern us here.

From PNK onwards, we find Whitehead advocating for a kind of nonmental perception as the necessary basis of any possible knowledge of the real world (the world populated by individuals rather than universals). From SMW onwards, however, he begins to introduce a distinction that necessitates a refinement in our question. For Whitehead comes to the conclusion that such non-mental perception would have to be pre-cognitive and pre-conscious. This is the "uncognitive apprehension" of SMW and the "unconscious experience" of PR. Thus, in PR Whitehead adopts "the principle $[\ldots]$ that consciousness presupposes experience, and not 
experience consciousness." 55 The question we have thus far posed, What is the eminent mode of cognitive access to individuals?, must therefore be reformulated as What is the eminent mode of experiential access to individuals? We will be able to return to the question of cognition or conscious experience of individuals only at the end of this investigation. I turn now to textual documentation of the eminence of what I am calling "non-mental perception" in Whitehead.

In $\mathrm{S}$ and PR Whitehead is explicit that it is only through non-mental perception that we can have any access to individual things other than ourselves. This is clear in the first place from PR's basic contrast between physical and conceptual (mental) prehension. The former takes account of individuals precisely because it is not mental; the latter fails to reach individuals precisely because it is abstract and grasps only universals. But the importance of non-mental perception is cast in stronger and sharper relief by Whitehead's more subtle distinction between two fundamentally different modes of perception: perception in the mode of presentational immediacy and perception in the mode of causal efficacy. Presentational immediacy is a form of perception dominated by mentality, while causal efficacy is a form of purely physical perception. Perception in the mode of causal efficacy is purely physical not in the sense that mentality plays no role in the way it comes to be (because mentality does play a role in the "subjective form" of all perceptions), but because its objects are physical individuals. The critical ingredients of mental perception are the universals Whitehead calls "simple eternal objects," by which he means qualia, which function as its principal objects insofar as they become localized in a geometrically structured object-space. The critical ingredient of physical perception is the causal action to which the experient is subjected by individual entities in its environment (this environment is not identical to the geometrically structured object-space of presentational immediacy, although by a process Whitehead calls symbolic reference the two can be correlated). By another name, this causal action upon the subject is its "prehension" of those agents as objects for it. ${ }^{56}$ Based on these distinctions we can say that Whitehead's candidate for eminent mode of experienceone that grasps concrete individuals rather than abstractions-is perception in the mode of causal efficacy (and his candidate for an eminent mode of cognition is presumably what he calls consciousness of perception in the mode of causal efficacy, as I discuss later). And this is well corroborated, for Whitehead is, in fact, quite explicit that the philosophy of organism transforms the traditional modern concept of intuition (which is the concept of intuition as an eminent mode) into that of prehension. ${ }^{57}$ 
Although Whitehead is nowhere as emphatic in advocating for the eminence of non-mental perception as he is in S and PR, it is nevertheless clear that he held a similar position much earlier. PNK and $\mathrm{CN}$ both operate with a distinction-not identical with, but very similar to the distinction between perception in the mode of causal efficacy and perception in the mode of presentational immediacy-between senseawareness of events and sense-awareness of objects: the former is related to individuals, the latter to the universals characterizing them. By making such a distinction Whitehead is ostensibly restricting the role of universals to a function that does not achieve individual reference. Taken as it stands, this implies that reference to individuals is a function in which universals (mentality) play no role. Although this conclusion will be soon qualified, it is nonetheless clear that sense-awareness of events is distinguished by a specifically non-mental moment.

Finally, we must consider whether the concept of an eminent, non-mental form of perception, which is implied by Whitehead's discussion of mentality in SMW's chapter on abstraction, can actually be found in any of the other chapters. For the chapter on abstraction (along with the chapter on God) is a late interpolation into that text and does not necessarily speak for the rest of the work. In fact, the concept we are looking for plays a prominent role in the all-important chapters III and IV, where Whitehead begins to construct the conceptual apparatus that will become his speculative philosophy. It must be conceded that a distinction between two kinds of perception is not made systematically in SMW, but it seems to be intimated in a passing contrast between "prehension" and the "ingression of sense-objects." ${ }^{158}$ In any case, however, a broader contrast, similar to PR's general contrast between physical and conceptual prehension, is patent. It is after all in SMW that Whitehead first introduces the term "prehension," which he does in order to create a contrast between a "cognitive" and an "uncognitive" way of perceiving or taking account of another thing: i.e., "apprehension" versus "prehension." Obviously modeled on Leibniz "perception without apperception," prehension is described as a natural process of unifying remote data. It is what abrogates the traditionally assumed constraint of "simple location," effectively referring to individuals at locations distant from its own place of occurrence. In short, SMW's "uncognitive apprehension" appears to be what I have already identified as non-mental perception in PNK, CN, and PR.

Our provisional conclusion, then, is the following. For Whitehead, intuition (properly reinterpreted as non-mental perception) is the eminent mode of experience. This would situate Whitehead on the right-hand side of our matrix, with the epistemological intuitionists, which brings us to our 
next question: is he to be placed in the upper quadrant, with Aristotle and Kant, or in the lower quadrant, with the Stoics? I will examine metaphysical criteria for making this determination shortly. Before doing that, I want to examine epistemological criteria, which come down to this: is experiential access to individuals the result of token-reflexive acquaintance or exhaustive specification?

4.1.2. We can translate the present question into Whiteheadian language in the following way. The virtue of non-mental perception is that it can reach concrete individuals because it escapes the finite limitations of mentality. But how does it escape these limitations? Does Whitehead's sense-awareness actually grasp the infinite complexity of the individual, or does it circumvent the necessity of doing this with the trick of tokenreflexive acquaintance? As a token-reflexive subterfuge for getting to where no thought can actually take us, effective sense-awareness would be a way to short-circuit the infinite path otherwise prescribed by concepts. But as an achievement of synthesis that is no longer mental precisely because it implies a description that is (would have to be) infinite, effective sense-awareness would be the realization of an actual infinity.

The latter possibility would have some surprising implications, which we should pause briefly to mention seeing that we will need to return to them later. It cannot be stressed too much that Whitehead thinks of the qualia of sense perception as universals. It is in light of this doctrine that we must consider the possibility that sense-awareness discloses individuals by assimilating their infinite specificity rather than by token-reflexive acquaintance. For this looks a lot like a roundabout rehabilitation of the epistemological logicism we thought Whitehead flatly rejected. But what Whitehead flatly rejects is actually something more specific. He denies universals the capacity to specify an individual insofar as they are functioning mentally. By itself, this does not preclude the possibility that they can also function non-mentally (intuitively) and as such succeed at picking individuals out by their unique specificity. (This second possibility also opens the way to a third possible interpretation: that Whitehead thinks intuition accesses individuals both by token-reflexive indication and by infinite qualitative specification, but discussion of this must be deferred to the very end of this paper.)

Granting a crucial role to token-reflexive acquaintance would push Whitehead into the upper quadrant with Aristotle or Kant (or possibly into the lower left quadrant with Leibniz, as I discuss below). Granting senseawareness the power to fully grasp the unique specificity of an individual would push him into the lower quadrant with the Stoics. For even if the Stoics did not stress the infinite character of an individual's specificity, 
they affirmed the two cardinal theses defining the lower right quadrant of our matrix. First, they endorsed the Principle of the Identity of Indiscernibles, which means they identified individuality with unique specificity. Secondly, while denying thought the capacity to reach all the way to the uniqueness of an individual, they specifically granted this capacity to intuition - at least in the ineffable extreme of discriminatory competence (i.e., katalepsis). Crucially, the success of intuition was not seen as the achievement of token-reflexive acquaintance with the individual, but as the consummation of the same process of specification thought was aiming at - in other words, as a kind of complete specification.

It seems obvious at first glance that Whitehead goes with the Stoics. For there can be no doubt that SMW represents thought as failing to conquer something that is simultaneously available to us: "it is impossible to complete the description of an actual occasion by means of concepts" means that finite description fails because the material actually given for description is somehow infinite (in its complexity or nuance, as expressed by the infinite abstractive hierarchy associated with it). This suggests that sense-awareness actually grasps the infinite complexity of individuals and constitutes the standard against which thought is seen to fail. But this conclusion is problematic. Such an infinite complex of eternal objects could only be the object of what PNK calls sense-awareness of objects, not sense-awareness of events, and it is expressly with the latter alone that Whitehead associates the grasp of individuals. This issue is complicated, however, by the fact that sense-awareness of events and sense awareness of objects are not really different acts of sense-awareness. Rather, they are distinct, yet inseparable aspects of one and the same sense-awareness:

There is no apprehension of external events apart from recognitions of sense-objects as related to them, and there is no recognition of sense-objects except as in relation to external events. ${ }^{60}$

The organic philosophy does not hold that the "particular existents" are prehended apart from universals; on the contrary, it holds that they are prehended by the mediation of universals. In other words, each actuality is prehended by means of some element of its own definiteness. ${ }^{61}$

Nevertheless, it appears that the contact with individuality is precisely what PNK's sense-awareness of objects and PR's objectification via eternal objects cannot contribute to the total complex act, and there does not seem to be any reason to qualify this conclusion for the case of an infinitely complex eternal object/object of sense-awareness:

[U]niversals are the only elements in the data describable by concepts, because concepts are merely the analytic functioning of universals. But the "exterior things," although they are not expressible by concepts in respect to their individual particularity, are no less data for feeling; so that the 
concrescent actuality arises from feeling their status of individual particularity; and thus that particularity is included as an element from which feelings originate, and which they concern. ${ }^{62}$

It seems, therefore, that we must grant the following two theses:

(1) The only thing capable of achieving reference to actual individuals is what PNK calls "event-awareness" and PR calls "perception in the mode of causal efficacy."

(2) Reference to individuals cannot be achieved by means of an infinitely complex sense-object/eternal object, because such an object would pertain only to PNK's sense-awareness of objects or PR's objectification via universals.

I add, as a third premise, the main thesis of my epistemological analysis of the problem of individuation:

(3) Reference to individuals is achieved either by token-reflexive acquaintance or by exhaustive specification.

If we grant these three premises, then, by exclusion, we are compelled to conclude that, for Whitehead, reference to individuals must be achieved by an essential token-reflexivity. This conclusion is evidently corroborated by the opening arguments of $\mathrm{CN}$, to which I now turn.

$\mathrm{CN}$ begins with reflections on what it means to know nature. In this context Whitehead lays enormous stress on the fundamental and indispensable role played by a purely indexical component in perception. Any account of how nature can be known must begin, he says, with an appeal to the inexplicable demonstrative power ingredient in senseawareness: "something perceived is perceived as an entity which is the terminus of [...] sense-awareness, something which for thought is beyond the fact of that sense-awareness." Thought, in other words, has to be about something that is not thought; perception has to be of something that exists independent of perception. Sounding like the later Franz Brentano, Whitehead says: "All thought has to be about things." To be thought, thought must transcend itself and make contact with what is beyond thought. But the possibility of self-transcendence is given to thought only by sense-awareness, which is possible in turn only because senseawareness transcends itself. Whitehead thinks the key to this selftranscendence is indexical or demonstrative reference (what might nowadays be called the crucial causal element that distinguishes "wide" content from "narrow" content), which is always embedded in senseawareness. Thought has a descriptive content that helps to conceptually disambiguate an act of demonstrative reference, but cannot explain it or substitute for it. That which thought is about is therefore not well indicated 
by a description of any sort (misdescription would otherwise be impossible), but rather by a demonstrative phrase like the pronoun "it" when employed in unambiguous contexts. However much the uniqueness of reference depends on conceptual disambiguation, there remains an indispensable achievement of causal reference that no amount of conceptual specification could have achieved on its own. Similarly, senseawareness has a describable content, but is not reducible to this describable content: misperception would otherwise be impossible. The indexical moment is always fundamental. Consider the following two passages from $\mathrm{CN}$ :

The "it' $[\ldots]$ presupposes that thought has seized on the entity as a bare objective for consideration. [...] The entity is so disclosed as a relatum in the complex which is nature. It dawns on an observer because of its relations; but it is an objective for thought in its own bare individuality. Thought cannot proceed otherwise; namely, it cannot proceed without the ideal bare "it" which is speculatively [roughly: successfully-meaning the reference has been understood] demonstrated. ${ }^{63}$

No characteristic of nature which is immediately posited for knowledge by sense-awareness can be explained. It is impenetrable by thought, in the sense that its peculiar essential character which enters into experience by sense-awareness is for thought merely the guardian of its individuality as a bare entity. Thus for thought "red" is merely a definite entity, though for awareness "red" has the content of its individuality. The transition from the "red" of awareness to the "red" of thought is accompanied by a definite loss of content [...] This loss in the transition to thought is compensated by the fact that thought is communicable whereas sense-awareness is incommunicable. ${ }^{64}$

In the passages intervening between the above two quotations, Whitehead systematically contrasts the role of demonstration, ${ }^{65}$ which is "impenetrable to thought" with the role of description, which obviously employs universals. From these comments it is easy to extract Whitehead's position regarding the relative importance of intuition and conception (thought), but also regarding the mechanism by which intuition achieves what thought cannot. By itself, no amount of description ever gets to real things, while demonstration does. Even if demonstration always presupposes a certain amount of description (which is to be expected if they are, as we established above, inseparable), what demonstration finally achieves is something for which no description (not even an infinite one) could substitute: the demonstrative indication of something beyond the content of experience, which nothing can vouchsafe except causal interaction with the thing being experienced. Demonstration is not something infinitely more nuanced than thought (a difference in quantity), but something wholly other and "impenetrable" to it (a difference in quality). 
If this conclusion is correct, what are we to make of the discussion in SMW's chapter on abstraction, which seems clearly to imply that intuition differs from thought precisely in that it discloses the infinite specificity of individuals, while thought does not? I will come back to this problem of reconciliation below.

4.1.3. Suppose we are (for the time being) satisfied with the conclusion that Whitehead belongs with those who insist on token-reflexive acquaintance as the only mode of access to individuals: we now face a third and more difficult question. Why exactly is this demonstrative intuition necessary? There are, after all, two possible reasons, each having very different implications. Is demonstrative intuition necessary because, although individuality is simply unique specificity, it is in each case an infinite specificity, making it impossible for us, with our finite means, to grasp an individual through its specificity? If so, the problem comes down to this: experience is always finite, while individuality is infinite. Hence, a finite trick for targeting individuals must be found, and this would be token-reflexive acquaintance. Or, on the contrary, is demonstrative intuition necessary because individuality involves a singularity beyond specificity, beyond even infinite specificity? If so, the possibility of "infinite experience" would not necessarily be excluded, but at the same time it would never be sufficient for access to individuals.

In the former case, intuition would be the eminent mode of access only by default. It would really be a remedial form of intentionality that succeeds at targeting an individual by the effective but undignified means of acquaintance, superior to thought only because thought, despite its intrinsically more dignified means of specification by universals descriptors, fails to achieve any reference at all when faced with the infinite specificity of individuals. On this account, individuality would still be unique specificity, as the Stoics or Leibniz believed, even if it could not be known by specification. Accordingly, intuition would play the role specifically ascribed to it by Leibniz, rather than the Stoics. It would have the same value that, according to Leibniz, a posteriori knowledge has for the finite mind. Empirical familiarity (a posteriori knowledge) offers to the finite mind something it would otherwise not experience at all. But an infinite mind knows a priori, without recourse to any empirical familiarity, the same truths that a finite mind is only familiar with empirically. Similarly, what token reflexive acquaintance would offer is fundamentally more than what finite thought could ever yield us, but fundamentally inferior to what infinite thought would yield if it were possible. The critical point is that, given the assumed nature of individuality, specification rather than acquaintance would be the ideal way to access it. It would only be the 
finitude of experience, not the nature of individuality itself that would keep us from accessing it by specification.

In the latter case, however, where individuality is singularity beyond specificity, intuition would be truly eminent because individuality would be something as qualitatively different from specificity as demonstration is from description, just as Aristotle or Kant believed. Here it is the very nature of individuality that prevents us from accessing it by specification. But here we have already crossed over to the metaphysical part of our examination of Whitehead's theory of individuation. So let's return now to the chapter on abstraction in SMW and, looking more closely at the theory of the infinite abstractive hierarchy, see what it implies about the principium individuationis.

\subsection{What Constitutes Individuality for Whitehead?}

In SMW Whitehead associates individuality with a description of infinite complexity. Limiting ourselves first to this text alone and leaving aside anything we have just learned from other texts: in allegiance to which faction should we construe Whitehead's theory of individuation in SMW? The answer to this question will depend on how we answer another question, which we must consider first: is Whitehead proposing the infinite abstractive hierarchy (hereafter: IAH) as a sufficient or just a necessary condition of individuality? Because the answer to this question is far from obvious, it will be instructive to consider both possibilities.

Suppose first that the IAH is intended as a sufficient condition of individuation. In that case, it is evident that Whitehead would be proposing an essentially Leibnizian theory of individuation. The significance of the infinite abstractive hierarchy would be that all individuals do differ in specie. Individuality would therefore be the same as specificity. Depending on whether we thought of intuition as grasping this specificity or just tracking it by way of the makeshift trick of token-reflexive acquaintance, we could place Whitehead in either of the two lower quadrants - with the Stoics or with Leibniz.

But we must note at once that there is a small but decisive qualification we would have to make to this interpretation, and it would go a long way towards mitigating the logicism of an otherwise very Leibnizian viewpoint. Individuality would be infinite specificity (a point that Leibniz concedes but does not stress as essential to the very nature of individuality). So Whitehead, on this interpretation, would ingeniously get to have it both 
ways. All individuals would differ in specie only, which means their differences would indeed be purely conceptual and reducible to purely universal qualifications. But each individual would nevertheless be infinitely nuanced or infinitely specific, which means that individuality could never be reduced to any finite set of universal qualifications. In principle, individuality would be something ineffable, something that always transcends conceptual thinking because mentality is always finite. From this perspective Whitehead's theory of individuation would seem to approximate more to the intuitionistic faction, which always emphasized the impossibility of capturing the individual in concepts alone and consequently the indispensability of something extra-logical, something extra-conceptual (aisthesis, intuitio, Anschauung, or token-reflexive reference) in becoming aware of or knowing an individual.

According to this interpretation of the IAH, we would have to say Whitehead disagrees with the intuitionistic faction, insofar as he does not believe that concepts (universals, eternal objects) are intrinsically incapable of specifying an individual. On the contrary, eternal objects would be all the forms of definiteness that things can have. As eternal objects functioning in an infinite abstractive hierarchy, "concepts" would — on this interpretation - constitute individuality. But Whitehead would agree with the intuitionistic faction as soon as concepts are construed psychologically as aspects of mentation. As such they are always, like everything mental, irremediably finite: each one of them will be finite in complexity, just as every composite description will be finite in its complexity (since the total number of concepts employed for any characterization will also be limited). As a function of mentation, then, universals will always be incapable of sufficient acuity to seize an individual by its unique description. But what is crucial here is that every individual would, at least in principle, have a unique description: it would differ from all other individuals in ways that did not depend on predicates relative to a token-reflexive anchor. So individuality would be infinite specificity, which transcends thought, but does not transcend specification by universals. On this interpretation, Whitehead's position would appear to come very close to that of the Stoics, who endorsed the Principle of the Identity of Indiscernibles, but denied thought the capacity to reach all the way to the uniqueness of an individual.

Before considering the alternative interpretation, let's note that there is an obvious problem with interpreting the IAH as a sufficient condition of individuation: it appears to be flatly contradicted by PR. Consequently, it seems we would have to assume Whitehead changed his position between SMW and PR in order to preserve this interpretation of the IAH. The testimony of PR is twofold, involving one of Whitehead's many forensic 
principles as well as direct statements. Regarding forensics, we have to consider the relevance of the pejorative "subjectivist principle," which Whitehead considers a fundamental fallacy: the idea that the datum in the act of experience can be adequately analyzed purely in terms of universals. Interpreting the IAH as a sufficient condition of individuality implies the following questionable thesis: the datum in the act of experience can be adequately analyzed in terms of an infinitely complex set of universals. The question is whether the qualification "infinite" salvages the subjectivist principle. Apparently it does not. Whitehead does think there is something of value in the subjectivist principle that deserves to be salvaged: it has to do with the way the most primary data for philosophy will always be facts having the form my perception that $S$ is $P$ rather than of the logically more straightforward form $S$ is $P$. But in PR Whitehead salvages the subjectivist principle through a reform that does not involve the infinite abstractive hierarchy (although to be sure the role of the IAH in individuation, perhaps as a necessary conditions, is not denied either), but rather involves the insistence that the objective relata of experience are themselves particulars, not universals. Proposed as a sufficient condition of individuation, however, the IAH would suggest the contrary: that the relata of concrete experience are not so much particulars as infinitely complex eternal objects. This reminds us of the fundamental difference in roles between "sense-awareness of objects" and "sense-awareness of events" in PNK and $\mathrm{CN}$. The IAH, since it has to do only with universals, seems relevant only to sense-awareness of objects. No improvements to the objective correlate of sense-awareness of objects (even making it infinite in complexity) can achieve what sense-awareness of events achieves, and it is only by recognizing the sui generis achievement of the latter that the valuable element in the subjectivist principle can be salvaged.

As for direct statements, nothing could be more explicit than the following:

[T] he "organic doctrine" demands a real essence in the sense of a complete analysis of the relations, and inter-relations of the actual entities which are formative of the actual entity in question, and an "abstract essence" in which the specified actual entities are replaced by the notions of unspecified entities in such a combination; this is the notion of an unspecified actual entity. Thus, the real essence [of an actual entity] involves real objectifications of specified actual entities; the abstract essence [of the same actual entity] is a complex eternal object. There is nothing self-contradictory in the thought of many actual entities with the same abstract essence; but there can only be one actual entity with the same real essence. For the real essence indicates "where" the entity is, that is to say, its status in the real world; the abstract essence omits the particularity of the status. ${ }^{66}$ 
Whitehead seems to be saying the same thing with the following briefer declaration:

One actual entity has a status among other actual entities, not expressible wholly in terms of contrasts between eternal objects. ${ }^{67}$

Individuality must be something beyond specificity, even infinite specificity, if there is more to an entity than what can be specified by contrasts of universals or, again, if there is no contradiction in the thought of multiple individuals satisfying the exact same type, where the type is specified by the complete ordered set of eternal objects characterizing it. According to these passages in PR, individuation seems to involve something beyond what eternal objects can specify, beyond what could be said about an entity presumably even in an infinite description. It requires, namely, the causal embeddedness of that entity in the real world. The individual is such and such a type of entity in this particular set of relations to other actual entities. This is consistent with the position we found Whitehead advocating in $\mathrm{CN}$ : causal embeddedness is the anchor for the token-reflexive acquaintance required for individuals to be recognizable. If this is Whitehead's position in PR, it explains the great stress he lays on token-reflexivity:

It must be remembered that the phrase "actual world" is like "yesterday" and "tomorrow," in that it alters its meaning according to standpoint. ${ }^{68}$

Just as Descartes said, "this body is mine;" so he should have said, "this actual world is mine. My process of "being myself" is my origination from my possession of the world. ${ }^{69}$

Taken together, these last four passages from PR suggest that individuation involves something unspecifiable that only token-reflexive acquaintance can discriminate. We should briefly consider the possibility that Whitehead thinks this token-reflexive element is only necessary for our discrimination of individuals because we are unable to pursue the process of conceptual specification to infinity. This would leave the door open to the possibility that in PR Whitehead does think the IAH is a sufficient condition of individuation, but not a sufficient condition of our ability to discriminate individuals. It would, in other words, be a sufficient metaphysical condition but not a sufficient epistemological condition of individuation. This will indeed suffice for a reconciliation of SMW's emphasis on the infinite specificity of individuals with CN's emphasis on an exclusively token-reflexive access to them, but it will not suffice for a reconciliation between SMW and PR. For in the longer passage from PR quoted above Whitehead says quite clearly that there can be multiple individuals of the same type, which implies that what SMW called the IAH is not a sufficient condition of individuation. Therefore, if Whitehead did 
believe that the IAH was a sufficient condition of individuation in SMW, he seems to adopt a new theory in PR. And if he does jettison the IAH as a sufficient condition of individuation, then his silence in PR on its residual status leaves its role in PR's theory of individuation uncertain. Does Whitehead abandon it entirely-because perhaps it is superfluous to his new theory of individuation? Or does he think of it merely as demoted in status so that it continues to play a role that is not insignificant, even if it is diminished, and that can be inferred, even if it is not discussed - the role perhaps of a merely necessary condition of individuation?

The other prima facie possibility is that in SMW Whitehead was proposing the IAH as a necessary condition of individuation only. If this is the case, there is not necessarily a conflict between SMW and PR. Although not mentioned explicitly in PR, we can consistently think of the IAH as continuing to play the same role it played in SMW.

Let's distinguish these two interpretations of the IAH as the strong interpretation (IAH is a sufficient condition of individuations) and the weak interpretation (IAH is only a necessary condition of individuation). The point we have arrived at so far is the following: the strong interpretation requires us to hold that PR rejects the position of SMW, while the weak interpretation allows us to view Whitehead's development as cumulatively consistent. But the strong interpretation also raises questions about continuity between SMW and CN or PNK. For the earlier books are very much like PR in stressing demonstrative indication rather than specification in connection with individuals. Construing the IAH as a sufficient condition of individuation seems to require us to hold that SMW deviatesin emphasis if not in doctrine-from PNK and CN, while PR expressly contradicts SMW and reaches back to the doctrine that SMW either contradicted or at least refused to emphasize. This seems prima facie implausible and militates against the strong interpretation. On the other hand, there are, as I argue below, decisive considerations that militate against the weak interpretation: there can in fact be no doubt that PR holds every individual to be typologically unique, which means that multiple individuals of the same type are actually impossible. This, of course, cries out for reconciliation with the passages just cited from PR, where Whitehead envisions the logical possibility of multiple identical instances and seems to give emphasis to the token-reflexive singularity rather than the infinite specificity of individuals. (This parallels the problem left unresolved in the previous section: how to reconcile the implication of SMW that intuition discloses the infinite specificity of individuals with the clear statements of $\mathrm{CN}$ and PR that disclosure of individuals is tokenreflexive?) 
The interpretation I propose is therefore neither of those just given, but one that is more complex. The problem is that we have still not taken account of two distinctions that are crucial to Whitehead's theory of individuation. One is the distinction between real and abstract essence; the other is the distinction between subjects and objects/superjects. Taking proper account of these distinctions, I believe it is not only possible to reconcile the ostensibly conflicting passages of PR with one another, but also possible to reconcile a strong interpretation of the IAH with the possibility of cumulative consistency. Thus, although it is obvious that Whitehead, as he progresses from PNK and CN to SMW and finally to PR, continues to develop a more and more complex and nuanced theory of individuation, there is, I suggest, at least one consistent reading of the final doctrine that offers a strong interpretation of the IAH and nevertheless does not require us to hold that SMW rejects the position of PNK and CN or that PR rejects the position of SMW.

There are two key elements to the proposed interpretation. One is that we apply the distinction between real and abstract essence to the IAH itself. We will then discover that the IAH as abstract essence is (in a special and restricted sense) capable of multiple instantiations and thus only a necessary condition of individuation, but as real essence is necessarily unique and thus a sufficient condition. (By the same token, we will see that only the abstract essence is externally related to its instances, while the real essence must be internally related.) The implication of this state of affairs is curious. Because the abstract IAH is infinitely specific without being individual, it seems to follow that individuality is more than specificity. But this means that the IAH as real essence, because it is individual, must be something more than its own specificity. How does the IAH as real essence succeed at becoming more than a function of universals so as to possess a singularity beyond its own specificity?

Understanding how this could be requires us to look at the role of subjectivity in producing the infinite specificity of the superject, which is the second key element of the proposed interpretation. However, what we will find is paradoxical: that the conditions for the emergence of new individuals in the world are such that every individual is of necessity specifically unique, which means that the infinite specificity of the IAH is, after all, sufficient for individuation! This seems to suggest that any further singularity is superfluous (if not non-existent). But if this is the case, then in what does the difference between the real and the abstract essence consist? Why is the same infinite specificity in the one case inadequate and in the other adequate for individuation? I propose that the only difference is the following: in the abstract essence the synthesis of eternal objects is not 
real but possible, while in the real essence alone is the synthesis real, the product of becoming that is contingent, historically dated, and subjectively motivated. This interpretation does have one somewhat unorthodox implication for Whitehead scholarship, which is that complex eternal objects are not eternal in the same way that simple ones are. It is only the possibility of their synthesis, not their synthesis that is eternal. Let's reconsider our approach before we proceed to grounding the proposed interpretation.

\subsection{Does Whitehead's Theory of Individuation Fall in the Blind Spot of Our Analytic Matrix?}

Before anything else, let's take note of a possibility that our analytic schema, while not prohibiting, nevertheless does not specifically envision. To say, as I have, that for purposes of individuation haecceitas would be superfluous to unique specificity (and vice versa) is not to say that they are incompatible. There is nothing contradictory in the notion of an individual whose individuality is overdetermined, possessing both unique specificity and haecceitas. Whitehead in fact strongly supports both theories of individuation-sometimes in the same book (e.g., PR). It is, of course, possible that he is vacillating back and forth, but we should not reject out of hand the possibility that he has reasons for wanting to combine both theories. In fact, I shall make the following argument. Just as phenomenology identifies what it calls a "genetic" fallacy-mistaking the conditions of a thing's coming-to-be for a description of what it isprocess philosophy identifies a complementary mistake, which we could call a "descriptive" fallacy: forgetting that what things are is something they have come to be. The descriptive fallacy results in the attempt to understand what things are by means of a timeless description as though they were wholly static phenomena (essences). The superfluousness of haecceitas to unique specificity will turn out to be a finding of "pure description." Avoiding the descriptive fallacy means recognizing important ways that unique specificity depends on haecceitas, and this, I propose, motivates Whitehead's embrace of both theories of individuation. I begin by showing how our analytic matrix is limited by an implicit descriptive bias.

So far we have considered the problem of individuation in terms of the traditional token-type distinction, distinguishing a specificity theory of individuation from a singularity theory of individuation based on the answer to the question: can there be more than one token of the same type? 
If the answer to this question is yes, then there must be something more to an individual's singularity than its specificity. In looking for this "more," we broached a number of traditional possibilities, such as accidental or relative predicates, space-time location or realization at different loci of the Receptacle, a formal property of thisness (haecceitas) added to the essence, or, as in Aristotle's composite substances, the contingent actuality of the type, which is ipso facto the singularity of an instance. But so far we have throughout our investigation taken a static view of the token-type relation, as if they were both given and we could compare them to decide what, if anything, the token possesses that the type does not. This is indeed a very common approach to the question. For example, the nineteenth century Platonizing logicians we have already alluded to postulated three realms of "being": the first was the material realm of physical nature; the second was the psychological realm of mental events; the third was the eternal realm of universals and the complex universals we are calling "types." The first realm is in both space and time; the second is temporal only; and the third realm is neither spatial nor temporal. The third realm in other words is entirely static. Consequently, by taking a material or psychological individual at an instant we can compare it with its static type and ask how they differ. (A static view of the token-type relation can also be taken by those who dismiss the third realm and see universals as mental entities: they are comparing tokens given in intuition and taken at an instant with their concepts of them as fixed in language or discursive analysis.) We have drawn a clear distinction between Whitehead and those who take a purely psychological view of concepts, but in the same breath we have insinuated a static view of the token-type relation into Whitehead: contrasting him with the psychological logicians by comparing him to the Platonizing logicians who postulated the third realm. Whitehead seems to invite this comparison by talking about "complex eternal objects" much the same way he talks about simple eternal objects and by stressing that eternal objects are related externally to their instances. But setting the problem up in this way ignores some of Whitehead's own caveats and in the end makes it impossible to discover the difference between a thing's abstract essence and its real essence. Since it treats the abstract essence as nothing but a hypostatized real essence, the abstract essence contains ipso facto everything that the real essence contains, and we are thus sent looking in strange places for what surplus the real essence might actually have over the abstract one. Intimately bound up with this Platonizing view of types as inhabiting a static, eternally pre-given realm of forms is an equally Platonizing view of the realm of instantiation. If types are externally related to their instances, then how many instances there are is a matter of indifference to the type, and so to the instances as well. Thus, our tendency 
in this paper has been to think of tokens as inhabiting a kind of Platonic Receptacle, where they stand in a loose array, mutually independent from one another: they participate in forms but are not necessarily or essentially related to one another. Whitehead's position diverges from the one just described in ways we need to examine.

The metaphysical scheme Whitehead advances in PR can be summarized as follows. Each real individual in the universe has two aspects to its existence. The primary or originative aspect is the process by which it comes to be. This is a process by means of which an individual arises at a discrete locus within the extensive continuum by absorbing, reconciling, and concretizing the ambient causal influences converging at that locus from all the antecedent individuals in the world. This process Whitehead calls concrescence. It is driven by the goal of achieving complete determinacy in relation to every possibility (yes, every possibility-hence the constitutive relevance of eternal objects to this process!). As long as this process is still underway, the entity in question is a subject. But once this process has achieved its goal, its animating nisus, because satisfied, expires, and what is left is something static, which Whitehead calls a superject. (Between process and stasis there is a moment of consummated self-enjoyment, the discussion of which I defer to the end of this paper.) Development and impulsion belong to a subject seeking concretion; stasis and permanence belong to it as a superject that has become concrete. Now what we have done so far in this paper is to assume that our tokens are superjects and to ask how they stand in comparison with their types. But by ignoring the dynamic aspect of instantiation we exaggerated the aloofness of the type. The relationship of the subject to the type is obviously more fundamental and illuminating than the relationship of the superject to the type, and we must consider this first, even if our ultimate goal is to understand the individuality of superjects. With Whitehead's metaphysical scheme in mind, we must consider two fundamental issues: (1) what is the status of the subject's individuality prior to the perfected realization of the infinitely nuanced superject it resolves into, and (2) what is the status of the $I A H$ prior to its realization in the superject, i.e., what is the relationship between the IAH and the subject realizing it?

(1) If the subject is (at least for most of its career) an inchoate individual that is seeking, but has not achieved, complete individuation, in what sense can we even say that the subject is an individual? And if it is not an individual, then what is it? Some kind of universal? Surely not some kind of universal since a subject is the agent of its own becoming and only individuals can be agents. The solution to this problem brings us to a theory of individuation that appears so far to have been overlooked in this paper. 
Despite the many theories we have looked at, we have considered only one type of individuation: individuation as the differential value distinguishing separate things. But this is individuation as a kind of "being for another," as Hegel would call it, and it is Hegel to whom we owe the theoretical grasp of a different kind of individuation: being-for-self. Self-reference constitutes a unique form of individuation that does not depend on any differential value. We can imagine twins who are identical in all respects, including their personalities and experiences, but they would nevertheless be distinct individuals - not because of any difference between them, but quite on the contrary because of something they have in common. Each of them instantiates the same relationship of immediate self-reference. Being self-related makes something ipso facto different from everything else that is self-related! That is the peculiar nature of selfhood. Each self is unique because it is related to itself rather than another, even if every self has exactly this property. That makes selfhood look a lot like haecceitas. Distinct selves are different in a sui generis way that defies any attempt to describe it or specify it conceptually with universals. In fact, self-reference is the ultimate form of token-reflexivity and a precondition of all other forms of token reflexivity: here and now have meaning only for something that experiences itself as here and now, and nothing can experience itself $a s$ anything if it does not experience itself.

From these observations we are entitled to conclude that self-reference as a form of individuation has not been overlooked in the earlier pages of this discussion, but rather made its appearance disguised as haecceitas whenever this was understood as intrinsically involving some kind of token reflexive acquaintance. It was not necessarily implied when haecceitas was conceived as being metaphysically independent of an epistemological anchor of this sort, which is how Aristotle or Scotus seem to understand it. But whenever token-reflexive acquaintance was seen as essential to what individuation is (and not just to knowing it), we were either dealing with or presupposing self-reference as the anchor (or null-point) of possible indication, where indication is functioning as a principium individuationis. Because Whitehead's subjects are to a significant extent self-referential, aiming at their own concretion, they are individuals in this Hegelian sense. This makes our picture of individuation in Whitehead more complex than we first assumed. Let's distinguish between differential individuation and self-referential individuation terminologically as d-individuation and sindividuation. Then we can say that subjects in Whitehead are-until the very moment of their final consummation-necessarily not d-individuated, but that they are s-individuated because they are the process of aiming at their own d-individuation. 
Now let's remind ourselves of our original question (can there be multiple individuals of the same type?) using our newly refined language. It seems that multiple subjects of the same type should be possible. For to begin with, subjects are not necessarily d-individuated. Insofar as they are subjects still becoming they have an underdetermined d-individuality, which would thus allow for multiple instantiation the way abstraction in sense three (from part one) does. Properly speaking, subjects still becoming are s-individuated. (The importance of this will become clear later when we discuss conscious experience.) But it belongs to the nature of sindividuation to allow for multiple instantiation. There can be as many things as you like that all say "I," and despite being identical they will all be successfully referring to something different. But what about dindividuals (superjects)? Can there be d-individuals according to Whitehead that are instances of the exact same type (namely, of the same IAH)? If there can be, then the IAH is not a sufficient condition of individuation; if there cannot be identical individuals, then the IAH is sufficient.

(2) To answer this last question we need to clarify the relationship between a subject and the IAH it ultimately realizes, for the question comes down to this: can more than one subject realize the same type? Determining this will help clarify what status the IAH can have "independent" of its realization, that is, in its status as "abstract essence." Let us note, first of all, that two s-individuals cannot aim at the same IAH for the simple reason that they cannot aim at the IAH at all: it cannot have the status of a mental object. Mentality is always finite. Thus, while only mentality can drive or motivate a synthesis, only a physical synthesis can be infinite. To know if there can be two identical individuals thus requires us to look at the conditions of physical synthesis, and we will see in fact that each physical synthesis must be typologically unique. Whitehead thinks that each thing in the universe is related internally to all other things that have, relative to it, already come to be. Being a token means being somewhere, and being somewhere means having a perspective on the universe that is unique to that locus. Each thing constitutes its own individuality as a double function of the singularity of the universe and its unique perspective on that one universe. It is easy to see that under these circumstances no two things can be completely identical in type. In order to be identical in type to something else, an actual occasion would have to be identical with something from which it is removed by some finite distance in space-time and with which it does not share a perspective. What it is would therefore have to be (at least in part) independent of its perspective on the universe, which is to say that its relation to (at least some of) the rest of nature would have to be external. Whitehead's idea that the universe constitutes an 
organic whole of which all the parts are internally related precludes the possibility of any two individuals being identical. ${ }^{70}$

These considerations are conclusive and force us to admit the IAH as a sufficient condition of individuality in PR. Each individual is necessarily associated with a unique IAH. The question we must now address is how to reconcile this with Whitehead's statements, also found in PR, about multiple identical instances and token-reflexive individuality, which seem to imply that individuality is more than specificity. The first thing to note is that the token reflexivity broached in PR (and, by retrospective implication, in $\mathrm{CN}$ ) characterizes the individuality of subjects and the extrinsically denominated individuality of things indicated within the token-reflexive experience of subjects, not the intrinsic individuality of superjects, which should exist independently of their being experienced. Infinite specificity is associated only with the latter kind of individuality, the d-individuality of superjects. There is therefore no contradiction in Whitehead's ascribing an individuating role to both specificity and token-reflexivity. The latter individuates subjects, the former superjects. Secondly, Whitehead is clear that it is the abstract essence, not the real essence, that can be multiply instantiated. This means we are quite safe in letting infinite specificity be a sufficient condition of real individuation, but this exacerbates the remaining question: what does the abstract essence lack so as to fall short of picking out an individual uniquely. Doesn't it of necessity have the same infinite specificity as the real essence?

I suspect that our mistake in approaching the problem of individuation in Whitehead was to ask in the first place if the same IAH could have multiple instances, as if the IAH had some being independent of its instances. And it is true that Whitehead speaks of "complex eternal objects" as though they existed eternally apart from their contingent instances. But this cannot be quite right. The crucial point I want to stress is that eternal objects are, as Whitehead himself insists, inherently abstract in sense one (from part one) above: the simple eternal objects all remain in the "isolation" of their disparate individual essences. Now what can this mean but that "complex eternal object" is a sort of oxymoron? Can eternal objects really be eternally pre-given in their manifold possible complexities? Isn't it the possibility of their combinations that is pre-given? Thus, Whitehead says, "we are discussing possibility; so that every relationship which is possible is thereby in the realm of possibility." "71 Whitehead's simple eternal objects must indeed have some kind of third-realm, Platonic-type being by virtue of being the ultimate conditions of all possibility in a world where possibility "actually" exists. But apart from this default being in the case of simples, eternal objects don't seem very much like denizens of the third 
realm. On the contrary, their composition into a complex seems to be parasitic upon the actual occasions that realize such combinations, rather than the occasions depending on the complex eternal objects. ${ }^{72}$

What I called in part one the relevance of the abstract to the concrete is the relevance of a possible, not an actual complex of eternal objects. A complex eternal object as such - not a possible one but one that enjoys the real togetherness of its component - can exist only as realized in an instance, which happens in one of only two ways: physically or mentally. The IAH cannot exist as something mentally realized because mentality is never infinite. The conclusion is that the IAH can only exist as something physically realized in the superject. One important consequence that follows from this is that the real essence is internally related to its necessarily unique instance. And this is just what Whitehead seems to be saying in the passages quoted above. But there is no reason why the abstract essence - the possibility of a synthesis - need be internally related to an instance. Indeed, it cannot be internally related since it remains possible whether there is an instance or not. This allows us to see why there is nothing contradictory in the idea of multiple individuals with the same abstract essence, even though no two individuals can actually be identical in type. For, as we noted before, if a type is externally related to its instances, it will be a matter of indifference to the type how many instances there are. There is consequently no logical reason why the abstract essence could not have multiple identical individuals, even if one and the same universe, because it is organically integrated and has the coherence of a Gestalt, could not contain both of them. There is no reason, for example, why the same IAH could not adequately correspond to one individual in each of a multitude of possible universes.

\section{Conclusion}

I return now to the question how we are to classify Whitehead's theory of individuation. The first conclusion to draw from the foregoing analysis is that Whitehead belongs, as we originally suspected, with those who think of intuition as an eminent mode of experience. His logicist tendencies are metaphysical, not epistemological. But in what does the eminence of intuition consist? We queried earlier if intuition (the "sense-awareness" of $\mathrm{CN}$, the "perception in the mode of causal efficacy" of S, the "physical prehensions" of PR) was to be understood as the realization of an actual infinity. It is clear that thought is deficient because it tries to grasp the individual through its specificity and cannot reach all the way to the 
individual's infinite specificity. It is not clear, however, if intuition transcends thought because it is the realization of the actual infinity thought was aiming for, or only because it is token-reflexive.

To be sure, concrescence is the realization of an actual infinity. But at the point where concrescence is consummated in an infinitely specific individual, the occasion in question is no longer a subject and no longer has any experience of other occasions at all. Must we, by contrast, say that as long as an occasion is still a subject it experiences an intuition that necessarily falls short of the infinite specificity of the world it is intuiting? This would mean that intuition never grasps the individuality of its objects by their unique specificity, but only by their causal relation to the act of intuition. I think this is going to far, however, for Whitehead clearly envisions a moment of consummated subjectivity, where the complete (infinite) determinacy that subjectivity was seeking has been realized, but is still being subjectively enjoyed. And, in fact, his description of this state is his gloss on the meaning of "individuality" in his philosophy:

Individuality - The individual immediacy of an occasion is the final unity of subjective form, which is the occasion as an absolute reality. This immediacy is its moment of sheer individuality, bounded on either side by essential relativity. The occasion arises from relevant objects, and perishes into the status of an object for other occasions. But it enjoys its decisive moment of absolute self-attainment as emotional unity. ${ }^{73}$

From this passage I think we are entitled to conclude that for every occasion there is a moment of overlap, where it is still an s-individual, but already a d-individual. This implies the overdetermined individuality I previously suggested as an overlooked possibility in our analytic matrix. Furthermore, it can be adequately expressed in the language of PNK, supporting my contention of continuity in Whitehead's theory of individuation: at the same time that the individual is, as sense-awareness of events, causally related to the real conditions of its own becoming (and so refers to itself and its world token-reflexively), this same individual's sense-awareness of objects will, as an intuition of the same antecedent world, be the realization of an actual infinity, describable only by an IAH. In the moment of absolute self-enjoyment, sense-awareness of objects therefore intuits the unique specificity (d-individuality) of the world and constitutes the unique specificity (d-individuality) of the subject, while sense-awareness of events intuits the token-reflexive singularity of the world (its causal relation to the subject) and constitutes the token-reflexive singularity (s-individuality) of the subject. This overdetermined individuality puts Whitehead's theory in both the upper and lower right hand quadrants of our matrix. 
It bears stressing that individuality in the moment of absolute selfenjoyment is overdetermined both epistemologically and metaphysically: epistemologically, because the subject intuits the individuality of objects both token-reflexively by their causal efficacy and typologically by their unique specificity; metaphysically, because the subject constitutes its own individuality as both a self-referential singularity and a unique specificity.

It remains for us to determine what the situation is before and after this phase of overlap between the entity's s-individuality and d-individuality. But first we must come back to the difficult question we deferred when we decided to talk about eminent experience of individuals as opposed to eminent cognition of individuals. The infinitely nuanced intuition I have just described is necessarily "unconscious." So if we are really asking about eminent cognition (i.e., conscious experience), we need to draw a different conclusion. Consciousness is, after all, something "mental," so consciousness of perception in the mode of causal efficacy would, presumably, not be any more able to access individuals by their specificity than a description overtly using universals. We can be sure of this conclusion not only on the grounds just adduced (that consciousness is something mental), but also on the grounds that consciousness is incompatible with the consummated d-individuation of the state Whitehead calls absolute self-enjoyment. Whitehead says expressly that "[n]o actual entity can be conscious of its own satisfaction; for such knowledge would be a component in the process, and would thereby alter the satisfaction., ${ }^{, 74}$ Since conscious experience can belong only to a pre-terminal phase of selfrealization, it can never be or be the experience of d-individuality. Therefore, to the very extent that it is conscious, "consciousness of perception in the mode of causal efficacy" will be unable to grasp individuals by their unique specificity. Cognition will always have to fall back on its token-reflexive involvement in the world it is experiencing. These conclusions about the individuality of the subject and object of conscious intuition can be generalized and apply to the individuality of the subject and object of any experience prior to the moment of absolute selfenjoyment. This answers the question of the nature of individuality prior to absolute self-enjoyment: it is (and intuits) token-reflexive individuality only.

The status of individuality after the moment of absolute self-enjoyment comes down to this: is Whitehead a metaphysical intuitionist or a metaphysical logicist about the individuality of the superject? This is the main question that has been driving my whole analysis of Whitehead's theory of individuation. Although the outline of my answer has already been given above, I propose to make one last indirect approach to this 
question by asking what is the eminent way of experiencing the superject's individuality. Specifically, is the token-reflexivity of conscious intuition, which has just been elucidated, an eminent or a deficient mode of experiencing individuals? For if it is deficient, then by implication the only individuality intrinsically possessed by the superject must be the typological individuality of unique specificity. But if it is eminent, then by implication the superject must, in addition to its unique specificity, possess an intrinsic haecceitas (an intrinsic non-typological individuality), for this alone could be the object of a token-reflexive acquaintance functioning as an eminent mode of access to individuality.

Let's note that the token-reflexivity of conscious intuition is precisely what Whitehead was describing in the extended passages quoted above from CN. It looks in some respects like intuition as Leibniz understood it: effective in putting us in relation to individuals by the trick of tokenreflexive acquaintance, but fundamentally lacking in clarity as to their specificity. Whitehead's concept of conscious intuition would therefore seem to belong in the lower left quadrant, with Leibniz and others who think of intuition as an indexical substitute for the clarity of an infinite definition, although in Whitehead's case it would be a substitute for something quasi-Stoic: an infinitely specific intuition. But this assumes, along with Leibniz, that the intuited individual possesses only unique specificity so that knowing it by token-reflexive acquaintance is a deficient way of accessing its individuality.

This seems to be a sensible conclusion. For the superject is, by definition, no longer s-individuated. Therefore, it cannot derive a more-than-specific singularity (a non-typological singularity) from self-reference. Where else can it derive such singularity? Perhaps it is only in relation to other sindividuals that it has any such singularity, that is, insofar as it is an object of their experience standing in causal relation to them. But this is singularity by extrinsic denomination and would obviously be a poor substitute for experiencing its intrinsic individuality, guaranteeing that conscious intuition is an essentially deficient mode of experiencing the object's individuality. If this is not Whitehead's view, the problem is to see how the non-typological singularity of an actual occasion can keep from "evaporating" as it turns into the superject.

On the interpretation advanced in this paper, Whitehead is both a metaphysical intuitionist and a metaphysical logicist not only regarding the individuality of the subject, but also regarding the individuality of the superject. In the case of the superject, however, this overdetermination is extremely hard to pin down. It comes down to the peculiar way that the superject both is and is not more than its specificity: the superject contains 
nothing more than its infinite description would contain, and yet it possesses an individuality that even its infinite description would lack. The reason is that the individual is the real togetherness of elements that are otherwise eternally arrayed as possible to combine. It seems impossible to say in what this reality consists except to defer the question by saying real togetherness is togetherness that is causally embedded in the one real world. Nevertheless, Whitehead's unusual metaphysical scheme does give us a little more explanatory traction than this. We said that every superject has a unique abstract essence, but that its individuality is nevertheless not just the uniqueness of its essence. It is the "reality" of that essence. We can make some sense of this difference if we take into account the subjective sindividuality from which real superjective d-individuality emerges. Real as opposed to abstract (or merely possible) d-individuality is individuality that results from a token-reflexive synthesis of the antecedently real universe, whose individuals, in turn, must satisfy the same regressive definition.

There is, therefore, a critical difference between Whitehead's position and the one I am calling logicist, although at the same time he makes concessions to logicism that none of the figures I have identified as intuitionists would tolerate. The principal concession is that every superject truly is a typological (as opposed to a merely token-reflexive) singularity. The superject cannot help but be typologically unique because Whitehead's universe has the coherence of a Gestalt. The critical difference is that the superject cannot help but be more than just an abstract typological singularity because the genesis of the type has the non-typological singularity of a (partially) self-referential synthesis. The d-individuality of the superject inherits the non-typological singularity of its genesis precisely insofar as it is an achieved, rather than a merely possible synthesis. The non-typological individuality of the superject is therefore a residue of the sindividuality of the subject from which it emerges. This non-typological singularity is most obviously reflected in the fact that the individual's unique description is eternal (indifferent to place and time) while the real togetherness of the elements in its unique description is something uniquely associated with a single place and time.

The interpretation of Whitehead's theory of individuation proposed here has the virtue of accounting consistently for a great deal of seemingly contradictory textual evidence. It might be objected that the interpretation goes too far, proposing that Whitehead does not in later works reject any of his own earlier positions on individuation. It is not, however, so implausible that he should incorporate earlier positions into more complex ones. There is also some, albeit limited, textual evidence that can be adduced in support of a claim for coherence between the positions of SMW 
and PR. First, the distinction between the real and the abstract has systematic value in both works, and we might reasonably expect the same language to be associated with the same doctrine. On the interpretation advanced here we can assert that PR's distinction between the real and the abstract essence corresponds exactly to SMW's distinction between real and abstract possibility. The abstract essence expresses an abstract combinatorial possibility; the real essence expresses a synthesis constrained by real possibility. Secondly, it is possible to find some adumbration in SMW of PR's emphasis on the crucial role of subjective activity in constituting the reality of an essence:

In any actual occasion $a$, there will be a group $g$ of simple eternal objects which are ingredient in that group in the most concrete mode. This complete ingredience in an occasion, so as to yield the most complete fusion of individual essence with other eternal objects in the formation of the individual emergent occasion, is evidently of its own kind and cannot be defined in terms of anything else. ${ }^{75}$

This adumbration in SMW of PR's concept of concrescence is consistent with an interpretation that finds the same concept of reality operative in both books. If "reality" is a togetherness of eternal objects that is itself not eternal, but is rather the result of a self-referential activity of synthesis, then we should expect Whitehead to associate reality with a process marked by an indefinable haecceitas, just as he does in the passage quoted. And far from excluding token-reflexivity from its analysis of intuitive experience, which an isolated reading of the chapter on abstraction might suggest, SMW makes its role explicit in the crucial chapter IV:

This unity of a prehension defines itself as a here and a now, and the things so gathered into the grasped unity have essential reference to other places and other times. ${ }^{76}$

This passage of SMW establishes continuity not only with the emphasis on the token-reflexive aspect of experience in PR, but also with the discussion of "demonstration" in CN. Thus, far from there being a vacillation between two positions, it seems that in each work we have examined Whitehead supports a dual theory of individuation that combines the IAH with the token-reflexive fact of acquaintance.

An unorthodox consequence of the interpretation advanced here is that all complex eternal objects are in a certain sense "created." Only the possibility of their combinations would be eternal and uncreated. However, there is a small but growing minority of voices in process scholarship arguing that Whitehead's metaphysical scheme demands the creation of "new" eternal objects. ${ }^{77}$ How their arguments compare to mine is a subject for further research. 


\section{Appendix: The Finitude of Mentality and God's Infinite Mind}

Based on passages in SMW I have claimed that mentality is defined by finite complexity (or "abruptness"), and I have assumed that this is also Whitehead's position in PR. But isn't the equation of mentality with finitude clearly contradicted by these passages from Part IV of PR, where Whitehead is discussing God's mentality?

One side of God's nature is constituted by his conceptual experience. This experience is the primordial fact in the world, limited by no actuality which it presupposes. It is therefore infinite, devoid of all negative prehensions. ${ }^{78}$

Conceptual experience can be infinite, but it belongs to the nature of physical experience that it is finite. ${ }^{79}$

A physical pole is in its own nature exclusive, bounded by contradiction: a conceptual pole is in its own nature all-embracing, unbounded by contradiction. The former derives its share of infinity from the infinity of appetition; the latter derives its share of limitation from the exclusiveness of enjoyment. $^{80}$

God is the infinite ground of all mentality. ${ }^{81}$

I don't think these passages stand in contradiction to the interpretation of mentality I have based on SMW. God's primordial nature is positively related to an infinite number of eternal objects, but each one has an "analytical character," i.e., is finite and abrupt, whereas the actual occasion realizes an infinitely complex eternal object (as does, I suppose, God's consequent nature) by subjecting the realm of possibility to a gradation of relevance. "Gradation" is the opposite of abruptness. The infinitude of conceptual experience is not one of depth, but of breadth, so to speak. Conceptual experience can simultaneously entertain an indefinite number of incompatible possibilities. But each one of them will be finite. Physical experience, by contrast, cannot realize incompatible possibilities and is thus necessarily limited (finite) in its range or compass. But the possibility it does realize will be infinite in its specificity, which means that it will be graduated rather than abrupt. 


\section{Notes}

1. W. H. Leue, "Process and Essence," Philosophy and Phenomenological Research 20.1, 1960, pp. 62-79.

2. It is perhaps not a coincidence that Aristotle, the philosopher most insistent that the complexity of a thing's essence is finite, is also the one most emphatic in rejecting essentialism, while the philosopher most emphatic in adopting essentialism, Leibniz, is the first to explicitly affirm that the complexity of a thing's essence is infinite.

3. As Whitehead explains: "These transcendent entities have been termed 'universals.' I prefer to use the term 'eternal objects,' in order to disengage myself from presuppositions which cling to the former term owing to it prolonged philosophical history. Eternal objects are thus, in their nature, abstract. By 'abstract' I mean that what an eternal object is in itself - that is to say, its essence - is comprehensible without reference to some one particular occasion of experience. To be abstract is to transcend particular concrete occasions of actual happening." (Science and the Modern World, op. cit., p. 159.)

4. R. Wiehl. "Prozesse und Kontraste. Überlegungen zur Ästhetik," Zeitwelten. Philosophisches Denken an den Rändern von Natur und Geschichte (Frankfurt 1998), p. 73.

5. A. N. Whitehead, Science and the Modern World, op. cit., pp. $159 \mathrm{ff}$.

6. Ibid.

7. Ibid.

8. Ibid., p. 169.

9. Ibid., p. 158.

10. The metaphysics of counterfactual relevance is something to which Whitehead assigns the highest importance. An adequate metaphysics of counterfactual relevance is, he feels, urgently needed in the modern world, and his own turn to metaphysics in Science and the Modern World is animated by this need.

11. A. N. Whitehead, Science and the Modern World, op. cit., p. 171.

12. Ibid., p. 167.

13. Ibid., p. 170.

14. Ibid. 
15. The following paragraphs will discuss what is tacitly implied here, namely, that nothing can be concrete that is not related to every eternal object. All this means is that a concretum is definite or decided in relation to every possibility: every predicate is either truly affirmed or truly denied in relation to it.

16. A. N. Whitehead, Science and the Modern World, op. cit., p. 169.

17. Ibid.

18. Ibid., pp. 169ff.

19. Ibid.

20. Ibid., p. 171.

21. "So far I have merely been considering an actual occasion in the side of its full concreteness. It is this side of the occasion in virtue of which it is an event in nature. But a natural event, in this sense of the term, is only an abstraction from a complete actual occasion. A complete occasion includes that which in cognitive experience takes the form of memory, anticipation, imagination, and thought." (Ibid.)

22. This assertion is subject to important qualifications that are discussed at the very end of this paper.

23. A. N. Whitehead, Science and the Modern World, op. cit., p. 171.

24. G. W. Leibniz, New Essays on Human Understanding, translated and edited by P. Remnant and J. Bennett (Cambridge 1981), pp. 229ff. [=Philosophische Schriften (Berlin 1962), Vol. VI, p. 229ff.]

25. Things of the same natural kind are things in the world of becoming with stable similarities: the stable similarity between two pieces of gold, for example, or, more importantly, the similarities between the cycles of periodic phenomena and between phenomena with the same periodic cycles - think of biological reproduction or meteorological phenomena evincing repeating closed cycles such as evaporation-precipitation. Not only do two sloths of the same age have relatively stable similarities, but any two sloths also evince a similar diachronic pattern or sequence of pairs of similar properties, from the characteristics of being an infant sloth to the characteristics of producing an infant sloth.

26. Aristotles, Analytica Posteriora, A 33 (89a2-6).

27. Ibid., A 2 (72a2-6), A 30-31 (87b19-88a18); Metaphysica A 2 (982a21-25).

28. Ibid., M 10 (1087a15-19); De Anima, B 5 (417a23-30). 
29. Ethica Nichomachea, Z 12 (1143b5-14), which should be taken together with the two references in the preceding footnote and probably with De Sensu et Sensibilia 6 (445b16-17) as well.

30. In his treatise "On the Kriterion and Hegemonikon" Ptolemy says in express contradiction to neo-Platonic views he cannot have been unaware of: "Hence it also follows that sense perception and thought deal with the same objects, though not in the same way." See P. Huby and G. Neal (eds.), The Criterion of Truth. Essays written in honour of George Kerferd together with a text and translation (with annotations) of Ptolemy's "On the Kriterion and Hegemonikon," (Liverpool 1989), p. 197.

31. On the prominence of this doctrine in Galen and its Stoic roots, see M. Frede's "Stoics and Skeptics on Clear and Distinct Impressions," Essays in Ancient Philosophy (Minneapolis 1987), pp. 151-176, and the passages he references, especially in Galen: "Cognitive [i.e., "kataleptic"] impressions are not only clear, as opposed to obscure (amudros cf. Alexander of Aphrodisias, De anima, 71.5ff.), they are also are distinct (ektypos; cf. Diogenes Laertius, Lives of Eminent Philosophers VII 46), as opposed to confused (sugkechumenos; cf. Sextus Empiricus, Adversus Mathematikos VII [=Adversus Logikos I] 171). To see what their distinctness is supposed to consist in, it will be useful to refer to a doctrine which is never explicitly attributed to the Stoics but which we do find in Hellenistic dogmatic medicine and of which we have some reason to believe that it is in part of Stoic origin. According to this doctrine, the discriminatory power of the senses far outruns the ability of the mind to conceptualize the object. Thus, if under normal conditions we see an object clearly, its features are represented in the impression in such detail that our concepts do not capture them in all their detail. Hence, though a normal impression, as a rational impression, has a propositional content, the way it represents the subject of the proposition cannot be exhausted by any number of propositions (cf. Galen's De locis affectis, Opera omnia Caludii Galeni, Vol. VIII, 86.12ff., 87.4, 117.6, 339.13, 355; De praesagitione ex pulsu, Opera omnia, op. cit, Vol. IX, 366.10; De sanitate tuenda, Corpus Medicorum Graecorum, Vol. V, Pt. 4, Fasc. 2 [Frede has Fasc. 1], p. 185, 16) [or in Kühn's Opera, Vol. IV, 423.4]" (Frede 1987, 161). The ancient sources cited are: (1) Alexander of Aphrodisias: De anima, Greek text in Alexandri Aphrodisiensis, Praeter commentaria scripta minora. De Anima Liber cum Mantissa, Consilio et Auctoritate Academiae Litterarum Regiae Borussicae, Edidit Ivo Bruns 1887 (Berolinii Typis et Impensis Georgii Reimer), 1-100; available in English as The De Anima of Alexander of Aphrodisias: A Translation and Commentary by Athanasios P. Fotinis (Washington 1980). (2) Diogenes Laertius: Lives of Eminent Philosophers, 
Greek text and English translation available in two volumes in the Loeb Classical Library, edited and translated by R. D. Hicks 1972 (Cambridge 1972). (3) Sextus Empiricus: Adversus Logikos [=Adversus Mathematikos VII-VIII] (Against the Logicians [=Against the Professors VII-VIII]), Greek text and English translation available in the Loeb Classical Library, Sextus Empiricus in Four Volumes, edited and translated by R. G. Bury (Cambridge 1967), Vol. II. (4) Galen: De locis affectis, Greek text in K. G. Kühn, Opera omnia Claudii Galeni, 22 Volumes (Hildesheim 2002), Vol. VIII, pp. 1-452, available in English as Galen on the Affected Parts translated by R. Siegel (Basle 1976); De praesagitione ex pulsu (On Prognosis by the Pulse), Opera omnia, op. cit., Vol. IX, pp. 205-430; De sanitate tuenda (On Hygiene) in Corpus medicorum Graecorum, Vol. V, Pt. 4, Fasc. 2 (Leipzig and Berlin 1923), pp. 1-198, or in Kühn, Opera omnia, op. cit., Vol. VI, pp. 1-452 available in English as $A$ Translation of Galen's Hygiene, by Robert Montraville Green, with an introduction by H. E. Sigerist (Springfield 1951).

32. Husserl's intuitionism is balanced by an equally pronounced commitment to a kind of Leibnizian logicism, as the next section will reveal. Each stage in his development can be seen as a different way to reconcile these two tendencies through different metaphysical or epistemological qualifications.

33. H. Rickert, Kulturwissenschaft und Naturwissenschaft (Tübingen 1915), pp. 31ff.; E. Cassirer, Substance and Function \& Einstein's Theory of Relativity, authorized translation by W. C. Swabey and M. C. Swabey (New York 1953), Part II, passim, especially pp. 232ff. and 254 [=Substanzbegriff und Funktionsbegriff. Untersuchungen über die Grundfragen der Erkenntniskritik (Berlin 1910), pp. 309ff. and 337].

34. Qualia are sometimes mistakenly added to the list of what things must count as universals in a Leibnizian universe. But in fact, the Leibnizian theory of individuation prohibits any two qualities from being identical, making all qualia distinct particulars that can have only generic properties in common. It is only on some variety of the intuitionist theory of individuation that qualia can be universals.

35. Anaxagoras, fr. 12; Diogenes of Apollonia, fr. 5 in H. Diels and W. Kranz, Die Fragmente der Vorsokratiker (Zürich/Hildesheim 1952), Vol II, pp. $37 \mathrm{ff}$. and $61 \mathrm{ff}$.

36. A. N. Whitehead, Process and Reality, op. cit., pp. 40ff., 75, 80, $159 \mathrm{ff}$.

37. From this perspective, the paramount "Realist" Scotus has more in common with the Nominalists than, say, Thomas Aquinas: albeit for very 
different reasons, Scotus and the Nominalists both hold that the singular individual is the true and proper locus of concretion, whereas Thomas denies that sensible individuals possess a concreteness proper to their singularity. Their distinction from others of they same type is something accidental, making it inferior to and less knowable than their species, which is the true locus of concretion. Thus, for Thomas, the "real" individuality of a thing does coincide with its specificity. Far from being something primitive, a thisness distinct from specificity is something specious. For the Nominalists, of course, the sensible singular is the locus of true individuality not because it has an inexplicable formal component that confers individuality, but because the relative and accidental differences distinguishing singulars from one another (including differences having to do with their serving as the designata of acts of token-reflexive indication) are all the individuality there is. To be sure, this implies a nominal agreement with Thomas: there is no distinction between thisness and specificity. But for Nominalists it is the idea of a specificity other than accidental singularity that is specious. This makes the sensible singular a true individual and intuition an eminent mode of cognition by default.

38. M. Dummett, Truth and Other Enigmas (Cambridge 1978), pp. 351357.

39. I leave aside the question of the origin of our knowledge of universals. It does not matter for our purposes whether they are encountered through a special kind of acquaintance (a direct acquaintance with universals) or are derived by some kind of abstraction from our acquaintance with particulars. In the latter case, acquaintance with particulars would play an indispensable role in providing us with our stock of universal concepts, but the validity of universals as explanatory tools would not depend on this fact about their manner of genesis or discovery. The independence of explanation-by-universals from acquaintance with particulars would therefore be in no way compromised by this genetic dependence of description on acquaintance for the acquisition of universal concepts. If it turns out that explanation is unable to achieve independence from acquaintance, it will have nothing to do with the conditions of acquiring universal concepts. It will have to do with the impossibility of explaining any particular fact without referencing some other particular fact among the explanantia.

40. F. W. J. Schelling, Schriften von 1799-1801 (Darmstadt 1982), p. 427.

41. W. T. Krug, Briefe über den Neusten Idealismus: Eine Fortzsetzung der Briefe über die Wissenschaftslehre (Leipzig 1801), p. 74; see also pp. 25ff., 29ff., $31 \mathrm{ff}$. 
42. G. W. F. Hegel, Jenaer Kritische Schriften, edited by H. Buchner and O. Pöggeler (Hamburg 1968), pp. 174-187.

43. P. S. Laplace, A Philosophical Essay on Probabilities, translated from the Sixth French Edition by F. W. Truscott and F. L. Emory, with an introduction by E. T. Bell (New York 1951), pp. 3ff. [=Essai philosophique sur les Probabilités (Paris 1819), pp. 2ff.]. Let it be noted that, as a matter of general principle, the deducibility of the future and the past from the present state of the world was not a new thesis. As an alleged necessary consequence of the principle of sufficient reason, it was already affirmed by Christian Wolff a century earlier (e.g., in his Psychologia Rationalis [1734], § 435). See C. Wolff, Gesammelte Werke, herausgegeben und bearbeitet von J. École, J. E. Hofmann, M. Thomann, \& H. W. Arndt (Hildesheim 1972), Abteilung II: Band 6, pp. 353ff.

44. F. W. J. Schelling, Schriften, op. cit., pp. 398ff. Comparison of these two passages also reveals an important difference between these two otherwise very similar concepts of science. Determinism is concerned with the deduction of events. For the deterministic paradigm, the defining characteristic of science thus becomes the ability to make successful predictions. For the Idealists, it was not events, but the classes of natural phenomena, that is, the kinds of things that make up the natural world that were to be deduced. In the one case nature is conceived as a diachrony of interdependent events, in the other as a synchrony of interdependent types.

45. E. Husserl, Logische Untersuchungen, Vol. II, Part. I: Untersuchungen zur Phänomenologie und Theorie der Erkenntnis, edited by U. Panzer (Haag 1984), I § 28, p. 95.

46. T. Nagel, The View from Nowhere (New York 1989).

47. E. Husserl, Logische Untersuchungen, op. cit., I § 28, p. 95.

48. E. Husserl, Die Krisis der Europäischen Wissenschaften und die Transzendentale Phänomenologie. Eine Einleitung in die Phänomenologische Philosophie, edited by W. Biemel (Haag 1969), p. 508.

49. M. Schlick, "Über das Fundament der Erkenntnis," Erkenntnis IV, 1934, pp. 96ff.

50. K. Popper, The Logic of Scientific Discovery (New York 1968), pp. 93-103 [=Logik der Forschung (Tübingen 1966), pp. 60-69].

51. Ibid., pp. 104-111 [= pp. 69-76].

52. H. Putnam, Mind, Language and Reality (Cambridge 1979), pp. $215-$ 271. 
53. Cicero, Academica, Latin text and English translation available in the Loeb Classical Library, Cicero in Twenty-Eight Volumes, Vol. XIX, De Natura Deorum \& Academica, edited and translated by H. Rackham (Cambridge 1979), II 57.

54. The Stoics would fully agree, however, in denigrating token-reflexive acquaintance.

55. A. N. Whitehead, Process and Reality, op. cit., p. 53.

56. Whitehead is not a dualist, and the fact that he distinguishes between something "mental" and something "physical" should not be misunderstood. By radically reconceptualizing what "mental" and "physical" mean, Whitehead thinks he can preserve a polarity that does not imply incoherence.

57. A. N. Whitehead, Process and Reality, op. cit., pp. 49, 54ff., $113 \mathrm{ff}$. 139, $151 \mathrm{ff} ., 242$.

58. A. N. Whitehead, Science and the Modern World, op. cit., p. 69.

59. Ibid., pp. 42, 69.

60. A. N. Whitehead, Principles, op. cit., p. 83

61. A. N. Whitehead, Process and Reality, op. cit., p. 152.

62. Ibid., p. 55.

63. A. N. Whitehead, Concept of Nature, op. cit., p. 8.

64. Ibid., p. 13.

65. In this context Whitehead uses "demonstration" in its etymological sense, from de-monstrare: to point out, indicate, designate, show. It is a question of ostension, not of proof, as when we employ a "demonstrative" pronoun or adjective (this, that) to indicate something in our environment.

66. A. N. Whitehead, Process and Reality, op. cit., p. 60.

67. Ibid., p. 229.

68. Ibid., p. 65.

69. Ibid., p. 81.

70. Already in 1919 G. E. Moore determined that the Principle of the Identity of Indiscernibles would necessarily hold in a world where all relations were internal; see his "External and Internal Relations," Proceedings of the Aristotelian Society 20, pp. 40-62.

71. A. N. Whitehead, Science and the Modern World, op. cit., p. 164. 
72. I leave for future discussion how this interpretation needs to be qualified in light of Whitehead's theological speculations in Process and Reality.

73. A. N. Whitehead, Adventures of Ideas, op. cit., p. 177.

74. A. N. Whitehead, Process and Reality, op. cit., p. 85.

75. A. N. Whitehead, Science and the Modern World, op. cit., p. 169 (emphasis added).

76. Ibid., p. 69.

77. M. Weber, Whitehead's Pancreativism. The Basics (Frankfurt/Lancaster 2006).

78. A. N. Whitehead, Process and Reality, op. cit., p. 345.

79. Ibid., p. 345.

80. Ibid., p. 348.

81. Ibid. 
